\title{
Satellite observations of chlorophyll, phytoplankton biomass, and Ekman pumping in nonlinear mesoscale eddies
}

\author{
P. Gaube, ${ }^{1,2}$ D. B. Chelton, ${ }^{1}$ P. G. Strutton, ${ }^{3}$ and M. J. Behrenfeld ${ }^{4}$ \\ Received 17 April 2013; revised 16 September 2013; accepted 22 October 2013; published 2 December 2013.
}

[1] Nonlinear mesoscale eddies can influence biogeochemical cycles in the upper ocean through vertical and horizontal advection of nutrients and marine organisms. The relative importance of these two processes depends on the polarity of an eddy (cyclones versus anticyclones) and the initial biological conditions of the fluid trapped in the core of the eddy at the time of formation. Eddies originating in the eastern South Indian Ocean are unique in that anticyclones, typically associated with downwelling, contain elevated levels of chlorophyll-a, enhanced primary production and phytoplankton communities generally associated with nutrient-replete environments. From analysis of 9 years of concurrent satellite measurements of sea surface height, chlorophyll, phytoplankton carbon, and surface stress, we present observations that suggest eddy-induced Ekman upwelling as a mechanism that is at least partly responsible for sustaining positive phytoplankton anomalies in anticyclones of the South Indian Ocean. The biological response to this eddyinduced Ekman upwelling is evident only during the Austral winter. During the Austral summer, the biological response to eddy-induced Ekman pumping occurs deep in the euphotic zone, beyond the reach of satellite observations of ocean color.

Citation: Gaube, P., D. B. Chelton, P. G. Strutton, and M. J. Behrenfeld (2013), Satellite observations of chlorophyll, phytoplankton biomass, and Ekman pumping in nonlinear mesoscale eddies, J. Geophys. Res. Oceans, 118, 6349-6370, doi:10.1002/2013JC009027.

\section{Introduction}

[2] Mesoscale eddies with radius scales of order $100 \mathrm{~km}$ are nearly ubiquitous features of the World Ocean [Chelton et al., 2011a]. Eddies are known to play an important role in the meridional transfer of heat and salt [Qiu and Chen, 2005; Roemmich and Gilson, 2001; Chaigneau et al., 2011], the nutrient enrichment of oligotrophic pelagic ecosystems [McGillicuddy and Robinson, 1997; Oschlies, 2002; McGillicuddy et al., 2007], and the horizontal advection of phytoplankton [Lehahn et al., 2011; Chelton et al., 2011b; Siegel et al., 2011]. One of the mechanisms generating vertical nutrient fluxes in eddy interiors is eddy-induced Ekman pumping that arises from the

Additional supporting information may be found in the online version of this article.

${ }^{1}$ College of Earth, Ocean and Atmospheric Sciences, Oregon State University, Corvallis, Oregon, USA.

${ }^{2}$ Now at Department of Applied Ocean Physics and Engineering, Woods Hole Oceanographic Institution, Woods Hole, Massachusetts, USA.

${ }^{3}$ Institute for Marine and Antarctic Studies and Australian Research Council, Center of Excellence for Climate System Science, University of Tasmania, Hobart, Tasmania, Australia.

${ }^{4}$ Department of Botany and Plant Pathology, Oregon State University, Corvallis, Oregon, USA.

Corresponding author: P. Gaube, Department of Applied Ocean Physics and Engineering, Woods Hole Oceanographic Institute, Mail Stop 9, Woods Hole, MA 02543, USA. (pgaube@whoi.edu)

(C2013. American Geophysical Union. All Rights Reserved. 2169-9275/13/10.1002/2013JC009027 interaction between eddy surface currents and winds, to generate upwelling in the interiors of anticyclones and downwelling in the interiors of cyclones. Such eddyinduced Ekman pumping has been shown to influence phytoplankton communities in the cores of mesoscale anticyclones [Martin and Richards, 2001; McGillicuddy et al., 2007]. The importance of this physical-biological interaction has been studied in detail with a coupled ecosystem model [Anderson et al., 2011]. The goal of this study is to investigate this eddy influence on chlorophyll-a concentrations (CHL) in South Indian Ocean (SIO) mesoscale eddies.

[3] The SIO is singled out for this analysis because of the uniqueness of the eddies in this region. In particular, anticyclones that form off the west coast of Australia initially have very high CHL content. Waite et al. [2007a] showed that large-amplitude anticyclonic eddies in the SIO are associated with anomalously high primary production compared with cyclones and the regions surrounding the eddies. It is shown in this study that this predisposes the CHL in the SIO anticyclones to be influenced by eddyinduced Ekman pumping.

[4] The reason for the distinction of anticyclones in the SIO is that this is a unique region both physically and biologically. The eastern boundary current in the SIO is the Leeuwin Current, which flows poleward year round and thus differs from the eastern boundary currents in other ocean basins. Anticyclonic eddies formed from the pinching off meanders of poleward-flowing eastern boundary currents preferentially entrain continental shelf water, which seeds the interiors of anticyclones with productive 
a) Percent Coverage of Daily SeaWiFS Chlorophyll-a Observations
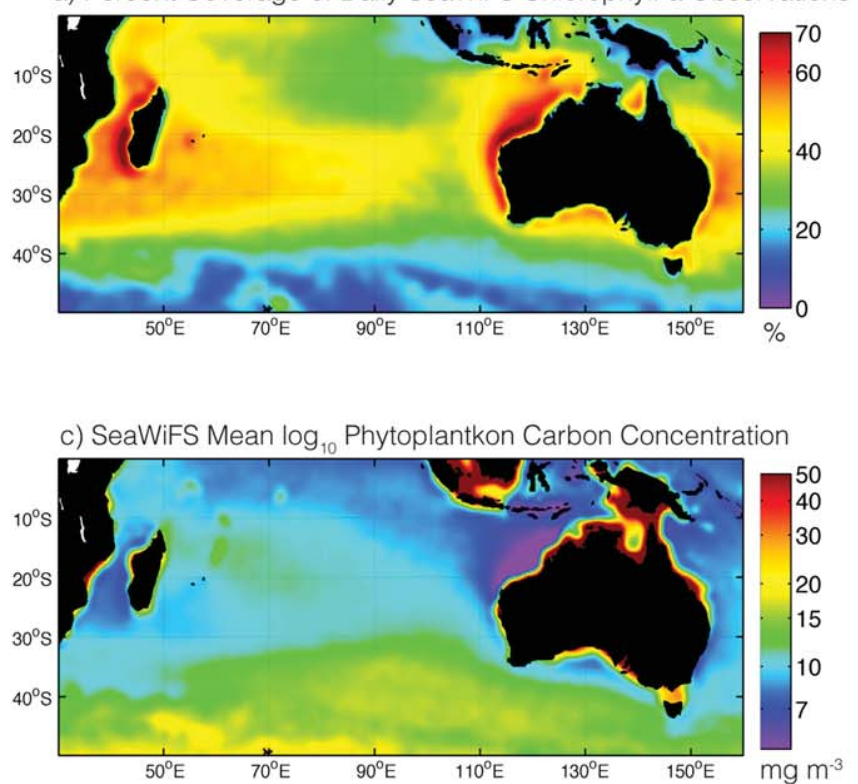

\section{b) SeaWiFS Mean $\log _{10}$ Chlorophyll-a Concentration}
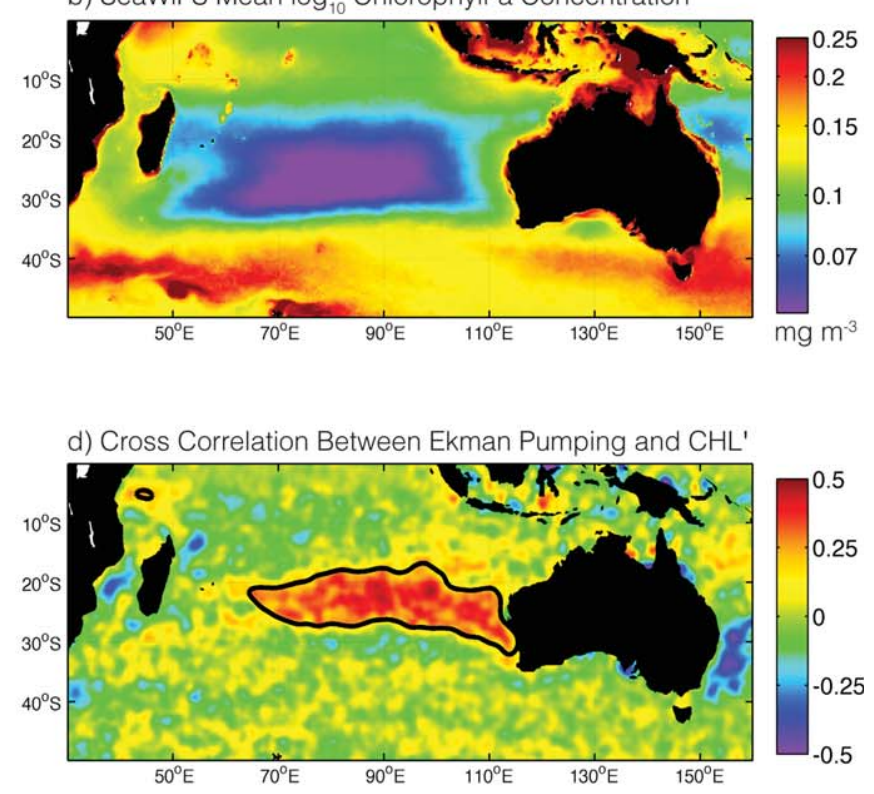

Figure 1. Maps for the South Indian Ocean showing: (a) the coverage of daily SeaWiFS CHL observations expressed as percent of maximum possible number of observations, (b) mean CHL from SeaWiFS calculated over the 8 year study period, plotted on a $\log _{10}$ scale, (c) mean $C_{\text {phyto }}$ from SeaWiFS calculated over the 8 year study period, also plotted on a $\log _{10}$ scale, and (d) cross-correlation coefficient between $\mathrm{CHL}^{\prime}$ and eddy-induced Ekman pumping velocity within eddy interiors.

(eutrophic) ecosystems that have locally elevated CHL and nutrient concentrations [Pearce and Griffiths, 1991]. These nutrients can be either in a biologically available form or already assimilated into marine organisms that can be recycled later, thus preconditioning the interiors of Leeuwin Current anticyclones to have elevated levels of primary production and phytoplankton concentration. On the other hand, cyclones that form in the Leeuwin Current entrain water from offshore during formation, resulting in trapped fluid that is low in nutrients and phytoplankton and referred to as oligotrophic. Observations confirm this distinction between anticyclones and cyclones in the eastern SIO [Thompson et al., 2007; Waite et al., 2007a].

[5] Fortuitously, the SIO is also a region with favorable clear-sky conditions, with much of the region permitting up to $60 \%$ of the maximum possible sampling of ocean color by the SeaWiFS instrument used in this study (Figure 1a). This allows relatively good spatial and temporal coverage of satellite ocean color measurements of CHL and other biological characteristics compared with most other ocean basins.

[6] The high CHL in Leeuwin Current anticyclones decreases rapidly after formation but still remains elevated relative to the surrounding waters throughout the lifetimes of the eddies. For these phytoplankton communities to be sustained at concentrations above the background levels, there must be a replenishment or efficient recycling of nutrients within the eddy interiors. Previous studies of anticyclones in the North Atlantic Ocean by Martin and Richards [2001] and McGillicuddy et al. [2007, 2008] have proposed a mechanism for the necessary nutrient supply. As originally pointed out by Stern [1965] and Dewar and Flierl [1987] and confirmed from satellite observations of surface stress over tens of thousands of mesoscale eddies
[Gaube, 2012], the surface currents in rotating eddies generate a curl of the surface stress with polarity opposite that of the vorticity of the eddy. Anticyclones thus generate cyclonic curl of the surface stress and hence upward Ekman pumping velocities that can upwell nutrients from below the euphotic zone.

[7] In the case of cyclones, the surface current-induced Ekman downwelling advects organisms downward and out of the euphotic zone. This is confirmed from a 2003 survey of a cyclonic Leeuwin Current eddy that was observed to be surface convergent. A drifter released away from the eddy center was retrieved 2 weeks later in the exact center of the cyclone [Waite et al., 2007a]. This surface convergence in Leeuwin Current cyclones is a common occurrence [Griffin et al., 2001] and is expected from the effects of eddy-induced Ekman downwelling from surface current effects on the surface stress field. The observations of surface convergence, and hence downwelling, suggest that CHL should be reduced within the euphotic zone, as was observed by Waite et al. [2007a].

[8] Martin and Richards [2001] hypothesized that eddyinduced Ekman pumping was a possible mechanism for sustaining an anomalous phytoplankton bloom that they observed in the core of a mode-water type anticyclonic eddy in the North Atlantic. An intensive ship survey by McGillicuddy et al. [2007] of another mode-type anticyclone in the Sargasso Sea showed the importance of eddy surface currentinduced upwelling. The phytoplankton concentrations within the core of the eddy was eight standard deviations higher than the mean background field. A sulfur hexafluoride tracer released at a depth of $\sim 100 \mathrm{~m}$ near the core of the anticyclone upwelled at a rate of $40 \mathrm{~cm}^{\text {day }}{ }^{-1}$, which compared well with the eddy-induced Ekman upwelling velocity 
calculated from satellite-derived surface stress curl values [McGillicuddy et al., 2007; Ledwell et al., 2008].

[9] A recent eddy-resolving coupled biogeochemical model of the North Atlantic seems to contradict the observed increase in primary production in response to eddy-induced Ekman pumping. Eden and Dietze [2009] concluded that eddy-induced Ekman pumping resulted in a $5 \%$ decrease in the integrated net primary production in the North Atlantic. This surprising decrease in primary production is likely attributable to an overall decrease of about $50 \%$ in the eddy kinetic energy (EKE) compared with their model runs that did not include the surface current effect on the surface stress. This is consistent with other recent modeling studies that have included the effects of surface currents on the surface stress [e.g., Hutchinson et al., 2010; Anderson et al., 2011; McClean et al., 2011]. The EKE decreases because the net effect of eddy-induced Ekman pumping is to attenuate the eddies [Dewar and Flierl, 1987; Gaube, 2012].

[10] When restricting the analysis to the interiors of mesoscale eddies in a coupled ecosystem model, Anderson et al. [2011] found that inclusion of eddy-induced Ekman pumping significantly affected not only the phytoplankton growth rates, but also phytoplankton community compositions. Phytoplankton biomass increased significantly in the cores of mode-type anticyclones. The biomass and growth rate of diatoms increased in non mode-type anticyclones as well. As in all other modeling studies, eddy-induced Ekman pumping from surface current effects reduced the amplitudes of all eddies in Anderson et al. [2011] simulation. Moreover, the upward displacement of shallow isopycnals decreased in the cores of cyclones and increased in the cores of mode-type anticyclones. For reasons that are not fully understood, the inclusion of eddy-induced Ekman pumping increased the relative abundance of mode-type eddies [Anderson et al., 2011].

[11] Another mechanism for eddy-induced Ekman pumping arises from eddy perturbations of the sea surface temperature (SST) field. SST influence on the overlying wind field has been studied extensively in SST frontal regions (see the reviews by Small et al. [2008] and Chelton and Xie [2010]). Park and Cornillon [2002] and Park et al. [2006] have shown from satellite measurements of winds and SST over Gulf Stream eddies that this same air-sea interaction also occurs over mesoscale eddies in association with eddyinduced perturbations of the SST field. In a companion paper, we show that SST-induced Ekman pumping occurs globally within mesoscale eddies but that this SST influence is usually secondary to the effects of surface currents on Ekman pumping (Gaube et al., manuscript in preparation, 2013).

[12] Eddy-induced pumping generates vertical velocities that diminish with depth in the seasonal pycnocline [Ledwell et al., 2008]. Quasigeostrophic theory stipulates a vertical scale of eddy-induced Ekman pumping of $f_{e} L / N$, where $f_{e}=|f+\zeta|$ is the effective Coriolis frequency, as modified by the vorticity of the eddy $\zeta, N$ is a buoyancy frequency characterizing the seasonal pycnocline, and $L$ is the horizontal length scale of the eddy. Using values representative of eddies of the SIO, $f_{e}=\mid-5 \times 10^{-5} \mathrm{~s}^{-1}+7 \times$ $10^{-6} \mathrm{~s}^{-1} \mid, N=0.016 \mathrm{~s}^{-1}$, taken as the maximum buoyancy frequency within the seasonal pycnocline as computed from climatological stratification data, and $L=100 \mathrm{~km}$, the vertical scale of eddy-induced Ekman pumping in SIO anticyclones is $\sim 350 \mathrm{~m}$, which is well below the depth of the euphotic zone.

[13] Eddy-induced Ekman pumping alone cannot generate a flux of nutrients across isopycnal surfaces. The sulfur hexafluoride tracer released by Ledwell et al. [2008] rose above the isopycnal within which it was released. The observed diapycnal transport of the tracer was attributed to the combined effects of solar heating and diapycnal mixing. From a modeling study of an idealized anticyclone with bio/physical characteristics chosen to match shipboard observations summarized in McGillicuddy et al. [2007], Ledwell et al. [2008] concluded that the observed nutrient flux within their anticyclone was driven primarily by eddyinduced Ekman pumping, while solar heating and diapycnal mixing allowed nutrients and tracers to be transported across isopycnals. The diapycnal flux of nutrients within anticyclonic eddies can further be enhanced by the trapping of near-inertial motions by virtue of their perturbations of the local vorticity field [e.g., Kunze, 1986]. In the study presented here, we focus on the role of eddy-induced Ekman pumping in generating the observed phytoplankton response in SIO eddies as Ekman pumping can be measured directly from satellites. In addition to the upwelling of nutrients within anticyclonic eddies by eddy-induced Ekman pumping, diapycnal mixing and solar heating would allow for nutrients upwelled in anticyclones to be mixed across isopycnals and into the euphotic zone. These two processes cannot be estimated from satellite and are therefore not investigated in this study.

[14] Surface current-induced Ekman pumping velocities within mesoscale eddies can exceed $1 \mathrm{~m}^{\text {day }}{ }^{-1}$ in largeamplitude eddies during strong wind events [Martin and Richards, 2001], but are more typically $\sim 0.1 \mathrm{~m} \mathrm{day}^{-1}$ [Gaube, 2012]. These velocities are thus small compared with the values of tens of meters per day estimated for submesoscale upwelling that occur along the peripheries of mesoscale eddies [Lévy et al., 2001, 2012]. However, unlike the upwelling associated with submesoscale variability that is generally transient, the upwelling in the cores of mesoscale anticyclones is persistent throughout the lifetime of the eddy. The magnitude of this upwelling is dependent on the strength of the background wind and the rotational speed of the eddy [Martin and Richards, 2001; McGillicuddy et al., 2007, 2008].

[15] The spatial structure of eddy-induced Ekman pumping generated by eddy surface currents is such that the vertical velocities are maximum in the cores of eddies. The eddy cores contain fluid that is trapped by the rotational velocities of the eddy [e.g., McWilliams and Flierl, 1979; Early et al., 2011]. The trapped core is thus isolated from the surrounding fluid, so that even small but persistent upwelling of nutrients from deep water into or out of the euphotic zone is important to the ecosystem trapped within the fluid. The response to the influx of new nutrients from upwelling in anticyclones should thus result in a positive CHL perturbation $\left(\mathrm{CHL}^{\prime}\right)$. Correspondingly, the $\mathrm{CHL}^{\prime}$ response to downwelling in cyclones is expected to be negative because both nutrients and phytoplankton are transported downward and out of the euphotic zone.

[16] Other mechanisms have been identified in idealized numerical simulations that could possibly aid in sustaining 
the observed CHL anomalies of SIO eddies [e.g., Klein et al., 1998; Lévy and Klein, 2004; Mahadevan et al., 2008]. From the satellite observations analyzed in this study, however, we are not able to resolve the scales at which most of these mechanisms occur. We therefore focus on eddy-induced Ekman pumping, which can be estimated from satellite scatterometers.

[17] The primary emphasis in this study is on CHL estimated from satellite measurements of ocean color [Garver and Siegel, 1997; Maritorena et al., 2002; Siegel et al., 2002]. Over its full global range of variability, satellitederived near-surface CHL is indicative of variability in the biomass of primary producers. Phytoplankton intracellular chlorophyll concentrations are, however, highly variable because of physiological acclimations to light availability, temperature, nutrient-driven changes in growth rate, nutrient limitation, and phytoplankton community composition [Laws and Bannister, 1980; Geider, 1987; Falkowski and LaRoche, 1991; Behrenfeld et al., 2008]. This "plasticity" must therefore be considered when interpreting the basis for CHL variability in natural phytoplankton communities, particularly when the observed dynamic range in CHL variability is relatively small (i.e., less than an order of magnitude).

[18] The adjustment of cellular CHL to the ambient light field is termed photoacclimation (cellular chlorophyll increases with decreasing light level). This physiological response can be problematic because intracellular CHL concentrations can vary by nearly an order of magnitude in response to changing light conditions alone [Behrenfeld et al., 2005]. In addition to CHL, we therefore also investigate the effects of eddies on phytoplankton carbon concentration $\left(C_{\text {phyto }}\right)$, a direct estimate of phytoplankton biomass that is insensitive to photoacclimation and can also be estimated from satellites [Behrenfeld et al., 2005]. With estimates of both CHL and $C_{\text {phyto }}$, information on variability of the CHL-to- $C_{\text {phyto }}$ ratio, hereafter referred to as $r_{C}$, can be retrieved. This provides insight into changes in phytoplankton growth rate and the light field (see section 2.3).

\section{Methods and Data Sets}

\subsection{Sea Surface Height and Eddy Tracking}

[19] This investigation of mesoscale biological-physical interactions is based on eddies with lifetimes of 12 weeks and longer that have been identified and tracked based on their signatures in sea surface height (SSH) [Chelton et al., 2011a]. The merged SSH measurements from two simultaneously operating altimeters allow the detection of mesoscale ocean eddies that are not resolved in SSH fields constructed from a single altimeter [Chelton and Schlax, 2003; Chelton et al., 2011a]. Merged SSH fields were obtained for the time period October 1992 through December 2011 from Collecte Localis Satellites (CLS/AVISO) at 7 day intervals on a $1 / 4^{\circ}$ latitude by $1 / 4^{\circ}$ longitude grid. The SSH fields used in this study are the Reference Series (REF) that is constructed by merging Topex/Posiden, Jason-1 or Jason-2 measurements with ERS-1, ERS-2, or ENVISAT [Ducet et al., 2000]. The wavelength resolution of the merged $\mathrm{SSH}$ fields is about $2^{\circ}$ in latitude by $2^{\circ}$ in longitude, which corresponds to Gaussian eddies with $e$ folding scales of about $40 \mathrm{~km}$ [Chelton et al., 2011a].
[20] As described in detail in Appendix B of Chelton et al. [2011a], mesoscale eddies were identified and tracked based on closed contours of SSH. The eddy amplitude at each weekly time step along its trajectory is defined to be the difference between the SSH extremum in the eddy interior and the value along the eddy perimeter, delineated as the outermost closed contour of SSH that defines a compact structure. The eddy interior is defined to be the region inside this SSH contour. The characteristic rotational speed of an eddy $(U)$ is defined at each point along its trajectory to be the average geostrophic speed along the SSH contour around which this quantity is maximum. The horizontal speed-based radius scale of the eddy, $L_{s}$, is defined to be the radius of a circle with area equal to that enclosed by this SSH contour.

\subsection{Ekman Pumping}

[21] Ekman pumping velocities were estimated from 10 $\mathrm{m}$ wind measurements by the SeaWinds scatterometer onboard the QuikSCAT satellite. The QuikSCAT mission began on 19 July 1999 and ended on 23 November 2009. Scatterometers infer equivalent neutral vector wind at $10 \mathrm{~m}$ relative to the moving sea surface [referred to as the relative wind, e.g., Ross et al., 1985; Chelton and Freilich, 2005]. Details of how Ekman pumping velocities were estimated from the QuikSCAT measurements can be found in Gaube [2012]. Briefly, relative wind vectors for each orbital period were gridded onto a $1 / 4^{\circ} \times 1 / 4^{\circ}$ grid using a low-pass filter with a half-power cutoff of $80 \mathrm{~km}$. The surface stress was estimated from the QuikSCAT equivalent neutral relative winds using the bulk formula

$$
\tau=\rho_{a} C_{D} \mathbf{u}_{r e l}\left|\mathbf{u}_{r e l}\right|,
$$

where $\rho_{a}$ is the air density (considered here to be constant and equal to $1.2 \mathrm{~kg} \mathrm{~m}^{-3}$ ) and $C_{D}$ is the speed-dependent drag coefficient for neutrally stable conditions that is appropriate for use with the equivalent neutral winds inferred from scatterometer measurements of radar backscatter. The curl of the surface stress $\nabla \times \tau$ was calculated in-swath and subsequently time averaged along with the relative wind speed and vector components. Ekman pumping was computed as

$$
W_{E}=\frac{\nabla \times \tau}{\rho_{o} f},
$$

where $\rho_{o}=1020 \mathrm{~kg} \mathrm{~m}^{-3}$ is the (assumed constant) surface density of sea water and $f=2 \Omega \cos \theta$ is the Coriolis parameter for latitude $\theta$ and Earth rotation rate $\Omega$. In this study, we choose to focus on the portion of Ekman pumping resulting from the curl of the surface stress (equation (2)), often referred to as "linear Ekman pumping," and neglect "nonlinear Ekman pumping," which results from the interaction of the surface stress with gradients in the surface current vorticity [e.g., Thomas and Rhines, 2002; Thomas, 2005; Mahadevan et al., 2008]. Although nonlinear Ekman pumping can result in vertical velocities with higher amplitudes than the linear Ekman pumping, vertical motions arising from the nonlinear terms tend to average out along rotational streamlines in eddy interiors [McGillicuddy et al., 2008]. Moreover, because the locations of the 
upwelling/downwelling cells associated with the nonlinear terms depend on the direction of the wind, they do not persist as long as those driven by linear Ekman pumping and as such do not afford as much time for a biological response to accumulated. Last, the resolution of the altimetrically derived surface currents is likely not sufficient to represent the most energetic nonlinear Ekman pumping, which takes place at the submesoscale.

[22] Since the wind field has scales larger than the $O$ $(100 \mathrm{~km})$ radii of SIO mesoscale eddies, the curl of the surface stress is attributable predominantly to the vorticity of the eddy surface currents. To be commensurate with the $\sim 35$ day $e$-folding timescale of the covariance function of the objective analysis procedure used by AVISO to process the SSH fields, the various wind fields considered in this study were constructed at the same 7 day intervals as the $\mathrm{SSH}$ observations with temporal low-pass filtering with a half-power filter cutoff of 30 days. The Ekman pumping fields were then spatially high-pass filtered with half-power filter cutoffs of $6^{\circ}$ of longitude by $6^{\circ}$ latitude to remove large-scale features unrelated to the mesoscale variability that is of interest in this study.

\subsection{Chlorophyll-a and Phytoplankton Carbon}

[23] Near-surface CHL and $C_{\text {phyto }}$ were estimated from measurements of ocean color by the SeaWiFS sensor onboard the Orbview-2 satellite. The SeaWiFS mission began on 19 September 1997 and ended on 10 September 2010. CHL and particulate backscattering coefficients at $440 \mathrm{~nm}\left(b_{b p}\right)$ were calculated using the Garver-SiegelMaritorena (GSM) semianalytical ocean color algorithm [Garver and Siegel, 1997; Maritorena et al., 2002; Siegel et al., 2002]. Phytoplankton carbon concentration $C_{\text {phyto }}$ was estimated from $b_{b p}$ as described in detail by Behrenfeld et al. [2005] by first subtracting a background value attributed to the scattering of nonalgal particles. The backscattering coefficient $b_{b p}$ was then scaled by a constant factor chosen to give values of the ratio $r_{C}=C H L / C_{\text {phyto }}$ that are (1) consistent with laboratory measurements of $r_{C}$ and (2) yield an average phytoplankton contribution to total particulate organic carbon of $30 \%$.

[24] Clouds are opaque in the visible spectrum. Data gaps during cloudy conditions must be taken into consideration when filtering the ocean color data in order to obtain reasonable estimates of CHL in eddies. The CHL fields were first $\log _{10}$ transformed and averaged onto the same $1 / 4^{\circ}$ grid as the SSH observations described in sections 2.1 . The log transformation accounts for the highly skewed distributions of the untransformed data in many regions of the World Ocean [Campbell, 1995]. The time series of daily CHL and $C_{\text {phyto }}$ values at each grid point were then lowpass loess filtered and gridded at weekly intervals to attenuate variability with periods shorter than 30 days and reduce data gaps from cloud contamination. The gridded CHL fields were then transformed back to linear concentrations. Although a historical precedent exists for analysis of the mesoscale anomalies of $\log _{10}$ transformed CHL [e.g., $U z$ et al., 2001; Cipollini et al., 2001; Killworth et al., 2004; Siegel et al., 2007, 2011; Chelton et al., 2011b], there is merit in analyzing anomalies of CHL and $C_{\text {phyto }}$ in the original units of $\mathrm{mg} \mathrm{m}^{-3}$ as it allows for direct comparisons of the results presented here to future satellite, in situ, or mod- eling studies. The conclusions of this study are shown in Appendix A to be insensitive to these details of how CHL and $C_{\text {phyto }}$ anomalies are created.

[25] The ratio $r_{C}$ was gridded and low-pass filtered in the same manner as the CHL and $C_{\text {phyto }}$ time series, except without $\log$ transforming because the range of variability of $r_{C}$ is small and is more symmetrically distributed than either CHL of $C_{\text {phyto }}$.

[26] To isolate mesoscale variability, the weekly maps of filtered CHL, $C_{p h y t o}$, and $r_{C}$ were spatially high-pass filtered with the same $6^{\circ} \times 6^{\circ}$ half-power cutoff that were applied to the Ekman pumping fields discussed in section 2.2. The biological variables are decomposed as

$$
\begin{gathered}
\mathrm{CHL}=\overline{\mathrm{CHL}}+\mathrm{CHL}^{\prime} \\
C_{\text {phyto }}=\overline{C_{\text {phyto }}}+C_{\text {phyto }}^{\prime} \\
r_{C}=\overline{r_{C}}+r_{C}^{\prime},
\end{gathered}
$$

where overbars denote the $6^{\circ} \times 6^{\circ}$ smoothed fields that are removed from the total fields to create the anomalies that are denoted with primes. To reduce filter edge effects caused by very high values of CHL near the coast, estimates of the anomaly values within a radial span of 6 grid points (approximately $150 \mathrm{~km}$ ) from any location identified as land were eliminated.

[27] The background, long-term averaged CHL concentration in the SIO vary in magnitude both geographically and seasonally, decreasing by more than a factor of two from values of about $0.13 \mathrm{mg} \mathrm{m}^{-3}$ in the vicinity of the Leeuwin Current to about $0.05 \mathrm{mg} \mathrm{m}^{-3}$ in the center of the oligotrophic SIO (Figure 1c). The magnitudes of CHL anomalies in both cyclones and anticyclones decrease similarly from the Leeuwin Current to the central SIO. Likewise, $C_{\text {phyto }}$ anomalies also vary geographically and seasonally resulting in inhomogeneites of the CHL and $C_{\text {phyto }}$ anomalies. The seasonal variability of both $\mathrm{CHL}^{\prime}$ and $C_{\text {phyto }}^{\prime}$ are of particular interest to the analysis presented in sections 3 and 4 and must therefore be retained. To help mitigate the effects of geographical inhomogeneity in the anomaly fields, we normalized the anomalies at longitude $x$ and latitude $y$ by the long-term averaged background fields at the same location,

$$
\begin{aligned}
\mathrm{CHL}^{\prime \prime}(x, y) & =\frac{\mathrm{CHL}^{\prime}(x, y)}{\langle\operatorname{CHL}(x, y)\rangle} \\
C^{\prime \prime}{ }_{\text {phyto }}(x, y) & =\frac{C_{\text {phyto }}^{\prime}(x, y)}{\left\langle C_{\text {phyto }}(x, y)\right\rangle}
\end{aligned}
$$

where $<>$ denotes the long-term, time-averaged background fields, which are available in digital form in the supporting information. The normalized CHL and $C_{\text {phyto }}$ anomalies are denoted by the double-primes and henceforth refers to as $\mathrm{CHL}^{\prime \prime}$ and $C^{\prime \prime}{ }_{\text {phyto }}$. Such a normalization is not required for $r_{C}^{\prime}$ because the range of variability is small in the SIO. This simple normalization addresses the geographical inhomogeneities of $\mathrm{CHL}^{\prime}$ and $C^{\prime}$ phyto and is preferred to others normalization procedures used in previous studies of mesoscale eddies, such as normalization by the local extremum of each eddy realization [e.g., Chelton et al., 2011a], as division by the mean field allows for easy conversion of normalized anomalies back into volumetric concentrations. Furthermore, the normalization addresses spatial inhomogeneities, 
allowing for composites to be created that include eddies formed offshore as well as those formed in the Leeuwin Current, resulting in a factor of 3 increase in the number of long-lived eddies used to construct the composite averages and statistics presented in section 3 .

\subsection{Collocation of Satellite Observations to the Interiors of Mesoscale Eddies}

[28] To assess the ecosystem response to eddy-induced Ekman pumping, the satellite-based estimates of Ekman pumping, CHL, $C_{\text {phyto }}$, and $r_{C}$ obtained as described in sections 2.2 and 2.3 were collocated to the interiors of each eddy realization identified from the altimeter data (section 2.1) for the 9 year period January 2001 through November 2009, during which concurrent measurements of ocean color, SSH, and Ekman pumping are available. The collocated values are referenced to the eddy centroid and interpolated onto a high-resolution grid with radial distance from the centroid normalized by the eddy radius scale $L_{s}$. This normalization allows composites to be constructed from hundreds to thousands of weekly eddy observations (depending on the subset of eddies chosen for the individual composites) on a common grid defined by the horizontal size of each individual eddy.

[29] Eddy-induced Ekman pumping in SIO eddies is primarily driven by the influence of ocean surface currents on the surface stress [Gaube, 2012]. The geographic structure of surface current-induced Ekman pumping consists of a monopole of upwelling/downwelling located at the center of anticyclones/cyclones, elongated somewhat in the direction of the wind [McGillicuddy et al., 2008; Gaube, 2012]. The CHL response to current-induced Ekman pumping should thus have a similar structure. To mitigate the effects of variable wind direction on the structures of Ekman pumping and $\mathrm{CHL}^{\prime \prime}$ within SIO eddies, we rotate each individual weekly eddy realization of $\mathrm{CHL}^{\prime \prime}$ and Ekman pumping to orient the background wind direction at a polar angle of $0^{\circ}$. This corresponds to no rotation for the case of westerly winds. The background wind direction was computed from $6^{\circ} \times 6^{\circ}$ smoothing of the QuikSCAT vector wind.

\subsection{Mixed Layer Depth}

[30] The mixed layer depth (MLD) can be defined from profiles of temperature, density, or both, based on the depth at which the vertical gradient is maximum. The MLDs in the interiors of SIO eddies were estimated for this study from Argo float profiles of temperature and salinity in the upper $1000 \mathrm{~m}$ at $70 \mathrm{~m}$ intervals with closer spacing in the upper $400 \mathrm{~m}$ (http://www.argo.ucsd.edu). Argo profiles were collocated to the interiors of the eddies selected for this study at the closest weekly time step to the time of each profile. An Argo profile was considered to be inside of an eddy if it occurred within the outermost closed contour of SSH used to define the eddy periphery. For the nearly 8 year overlap of the altimeter and Argo float data record, totals of 1593 and 1321 profiles were collocated to SIO cyclones and anticyclones, respectively (Figure 2).

[31] A density-based estimate of the MLD for each collocated Argo profile was obtained from the global data base compiled by Holte and Talley [2009]. The seasonal cycles of MLD from collocated profiles were calculated separately
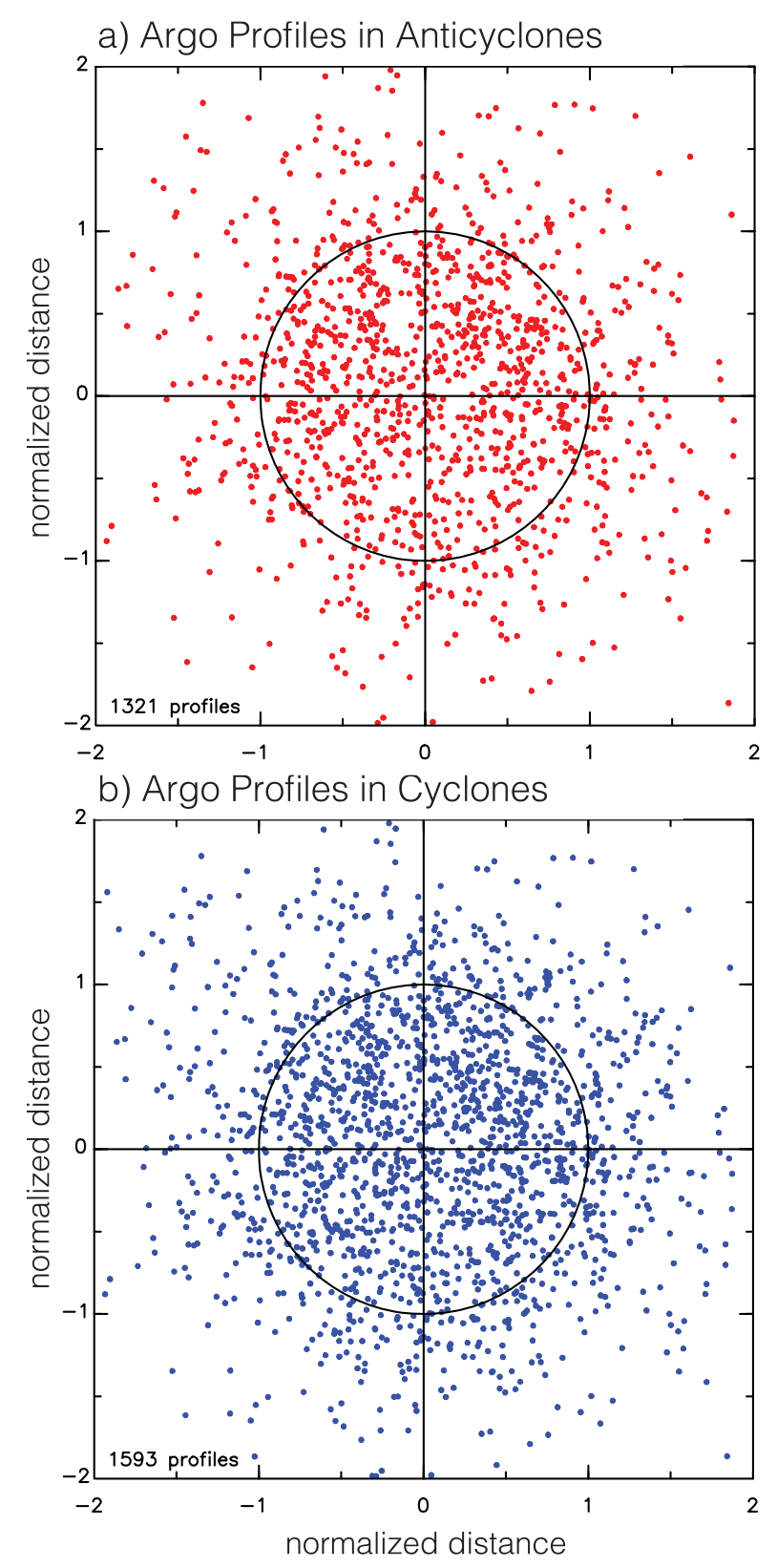

Figure 2. Locations of individual Argo float profiles that occurred within (a) anticyclonic and (b) cyclonic eddies in the SIO. Argo floats were collocated to the interiors of eddies using the outermost closed contour of SSH that enclosed the eddy centroid. The $x$ and $y$ location of each Argo profile relative to the eddy centroid has been normalized by the radius scale $L_{s}$ of the eddy realization nearest in time to the profile. Profiles occurring outside of the circle with radius $L_{S}$ occur because the outermost closed contour of SSH always occurs at larger radial scales than $L_{s}$, as well as the noncircular shape of most eddies [Chelton et al., 2011a].

for cyclones and anticyclones by regressing the time series of MLD onto the annual cycle and its first harmonic.

\subsection{Median Mixed Layer Growth Irradiance and Phytoplankton Growth Rate}

[32] The ratio $r_{C}=C H L / C_{\text {phyto }}$ used here to provide insight into physiological processes occurring at the 
community level varies primarily as a function of photoacclimation and phytoplankton growth rate [Laws and Bannister, 1980; Geider, 1987; Behrenfeld et al., 2005]. In previous studies, the two contributions to $r_{C}$ variability have been deconvolved by solving for the former component using information on mixed layer depth, the diffuse attenuation coefficient, and incident light level [Behrenfeld et al., 2005; Westberry et al., 2008]. The mixed-layer light field has been based on the output of a non-eddy-resolving, data assimilating global ocean model. Because of our interest is in bio/physical interactions in the interiors of mesoscale eddies, a similar approach could not be taken here. We can, however, estimate growth rate directly in eddies for which MLD is estimated from the Argo float profiles.

[33] Following Behrenfeld et al. [2005], the growth rate $\mu$ of the phytoplankton community in units of number of cell divisions per day can be estimated at the location and time of each individual Argo float profile by

$$
\mu=\mu_{\max }\left(r_{C} / r_{C}^{\max }\right)\left(1-e^{-3 I_{g}}\right),
$$

where $\mu_{\max }$ is the maximum potential growth rate of the phytoplankton community, which is estimated as 2 day $^{-1}$. The multiplicative factor $\left(1-e^{-3 I_{g}}\right)$ is an adjustment to account for a decrease in $\mu$ at low light levels where physiological adjustments in pigment concentration are insufficient to maintain constant levels of light absorption. The parameter $r_{C}^{\max }$ was estimated as described by Behrenfeld et al. [2005] based on an empirical fit to global observations of $r_{C}$ made by SeaWiFS for the mixed layer growth irradiance $I_{g}$ experienced by the photoautotrophic commu-

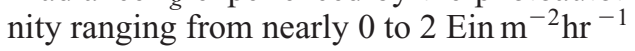

$$
r_{C}^{\max }=0.22+(0.045-0.022) e^{-3 I_{g}} .
$$

[34] Growth irradiance $I_{g}$ was computed from individual Argo profiles following the method of Behrenfeld et al. [2005]:

$$
I_{g}=\mathrm{PAR} e^{-k_{d} \mathrm{MLD} / 2}
$$

where PAR is the photosynthetically active radiation and $k_{d}$ is the diffuse attenuation coefficient at $490 \mathrm{~nm}$ as observed by SeaWiFS, both of which were obtained as daily, $9 \mathrm{~km}$ gridded fields. These data were bin averaged onto our $1 / 4^{\circ}$ grid and interpolated and low-pass filtered in time with the same 30 day half-power filter cutoff that was applied to the $\mathrm{CHL}, C_{\text {phyto }}$, and $r_{C}$ fields.

[35] In total, 628 and 684 direct estimates of $\mu$ were made in cyclonic and anticyclonic SIO eddies, respectively. The number of $\mu$ estimates differs from the total number of Argo profiles because of occasional missing CHL and $C_{\text {phyto }}$ values during periods of persistent clouds.

\section{Results}

[36] Mesoscale eddies in the SIO propagate westward with small equatorward deflections of anticyclones and poleward deflections of cyclones [Morrow et al., 2004; Chelton et al., 2011a]. After leaving the productive regions of the Leeuwin Current, eddies propagate far into the oligotrophic SIO. Eddies formed from the pinching off of anticy-

\section{a) Trajectories of Anticyclones}

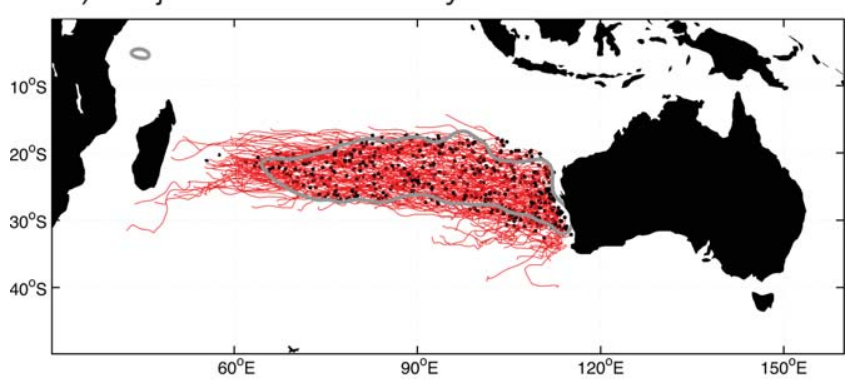

\section{b) Trajectories of Cyclones}

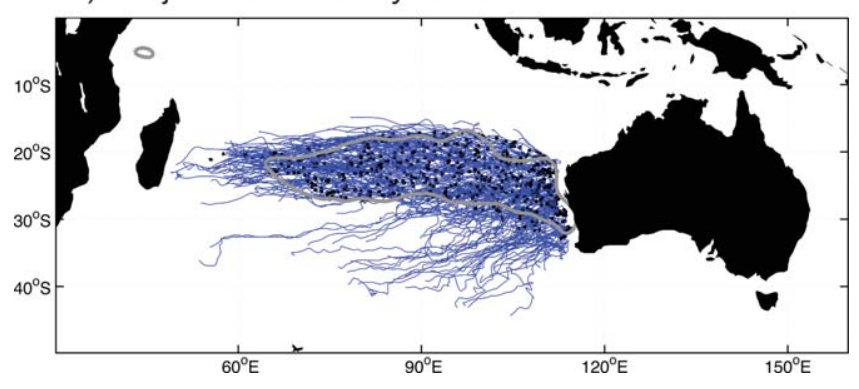

Figure 3. Trajectories of the (a) anticyclonic and (b) cyclonic eddies investigated here. The start location of each eddy is marked with a black circle. The 0.2 contour of smoothed cross correlation between $\mathrm{CHL}^{\prime}$ and eddyinduced Ekman pumping velocity (Figure 1d) is shown in gray. This contour is used to select eddy realizations from which composite averages are constructed and statistics are calculated. See section 3 for justifications of the use of this contour and section 4 and Appendix B for a discussion of differences in the results for these eddies and eddies originating only in the Leeuwin Current.

clonic meanders that contain coastal waters with high CHL and nutrients are of particular interest for the present study. These anticyclones propagate to the west-northwest into a region of low ambient CHL concentration (Figures 3a and $1 \mathrm{~b})$, where there is strong positive cross correlation between chlorophyll anomalies and Ekman pumping velocity inside eddies (Figure 1d).

[37] To investigate the relationship between eddyinduced Ekman pumping and CHL, composite averages were computed in normalized and rotated radius coordinates (see section 2.4) from all the eddies within the smoothed contour of 0.2 in the cross-correlation coefficient in Figure 1d. The 0.2 cross correlation threshold was chosen to focus on eddies that appear to respond to eddy-induced Ekman pumping. The eddies in this threshold region also happen to avoid strong meridional gradients of CHL to the north and especially to the south of the study region (this does not preclude the threshold region from having weaker meridional CHL gradients, as can be seen in Figure $1 b$ ). The CHL variability in eddies in such regions of strong meridional CHL gradients is dominated by the rotational advection of the background $\mathrm{CHL}$ gradient around the eddy peripheries [Chelton et al., 2011b] rather than by the Ekman pumping process that is of interest in this study. It will be shown, however, that even with the efforts made to avoid regions of strong background CHL 
a)
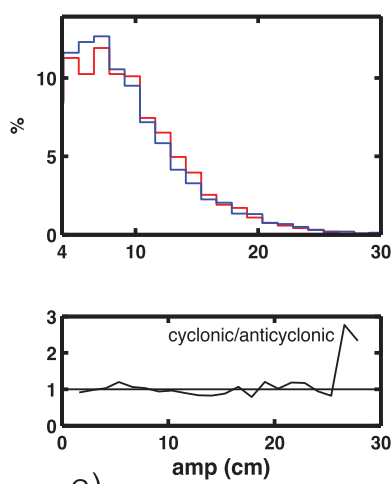

c)
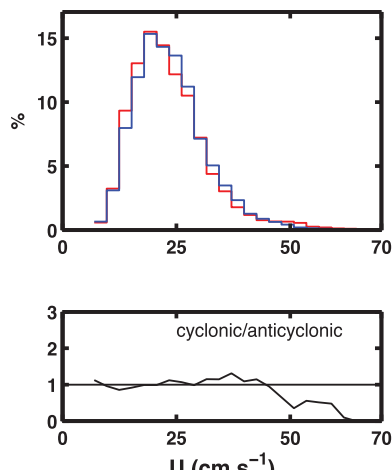

e)
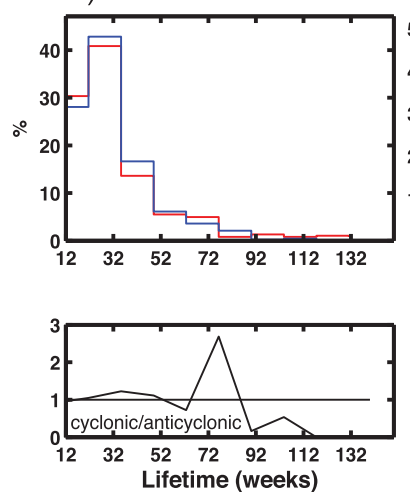

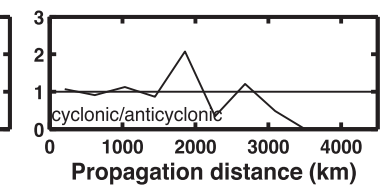

b)
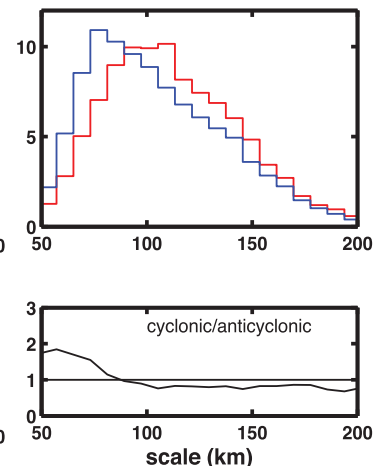

d)
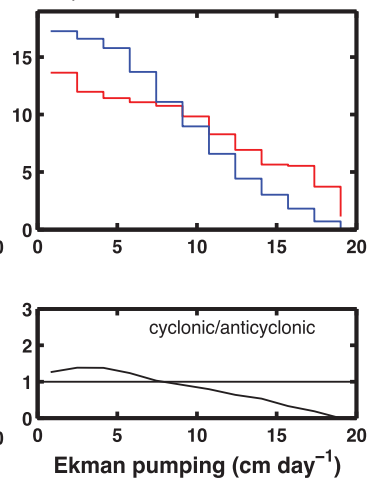

f)

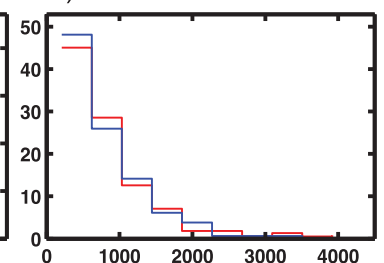

Propagation distance $(\mathbf{k m})$
Figure 4. (top) Histograms with cyclones shown in blue and anticyclones in red and (bottom) the ratio of cyclonic to anticyclonic: (a) eddy amplitudes; (b) eddy radius scales $L_{s}$; (c) maximum rotational speeds $U$ of the eddies; (d) magnitude of eddy-induced Ekman pumping within $L_{s} / 2$ of the eddy centroids; (e) eddy lifetimes; and (f) propagation distances. Figures $4 a-4 c$ and $4 \mathrm{e}-4 \mathrm{f}$ are computed from the full 19 year SSH data record, Figure 4d is computed from the full 10 year QuikSCAT data record.

gradient, in the absence of a CHL response to eddy-induced Ekman pumping, the advection of CHL around eddies can be observed in composite averages of $\mathrm{CHL}^{\prime \prime}$.

[38] There were 474 cyclonic and 382 anticyclonic eddies with lifetimes of 12 weeks and longer within the region of $\geq 0.2$ cross correlation during the 9 year analysis period January 2001 through November 2009. Each weekly observation is referred to here as an eddy realization. In total, there were 9507 realizations of cyclones and 8314 realizations of anticyclones during the 9 year period. On average, then, there are about 20 realizations of each cyclone and about 22 realizations of each anticyclone.

[39] SIO eddies have an average amplitude of $7.6 \mathrm{~cm}$, with no significant difference between cyclones and anticyclones. For amplitudes larger than $25 \mathrm{~cm}$, however, a larger percentage of the eddies are cyclonic (Figure 4a). The average radial scale, $L_{s}$, of SIO eddies is $107 \mathrm{~km}$ and $97 \mathrm{~km}$ for anticyclones and cyclones, respectively, with a larger percentage of cyclones having somewhat smaller radial scales (Figure 4b).

[40] The vorticity of surface currents generates Ekman upwelling and downwelling in the interiors of anticyclones and cyclones, respectively. These surface current effects are modulated by Ekman pumping from the SST influence on surface winds, which has more complicated spatial structure. As is usually the case globally, this SST-induced contribution to the total eddy-induced Ekman pumping in the SIO is secondary to surface current effects [Gaube, 2012]. Histograms of the magnitudes of eddy-induced Ekman pumping averaged within $L_{s} / 2$ of the centroids of SIO eddies reveal that the largest Ekman pumping velocities occur mostly in anticyclones (Figure 4d). This is because the eddies with the largest rotational speeds $U$ are predominately anticyclones (Figure 4c).

[41] Composite averages of the normalized CHL anomalies, CHL", and eddy-induced Ekman pumping, both computed in the rotated coordinate system defined by the wind direction (see section 2.4), are shown in Figure 5 for each calendar month. The strong seasonal cycle of $\mathrm{CHL}^{\prime \prime}$ is striking. During Austral winter (May through October), positive CHL" in anticyclones coincide almost exactly with contours of Ekman upwelling (the statistical significance of the $\mathrm{CHL}^{\prime \prime}$ is quantified in Appendix C). Likewise, negative $\mathrm{CHL}^{\prime \prime}$ in cyclones coincide almost exactly with contours of Ekman downwelling from March through September. In contrast to the high wintertime correlation, eddy-induced Ekman pumping has little influence on CHL" in eddies during the Austral summer (November through April). This is evident from the contours in Figure 5, which show that Ekman pumping is actually somewhat stronger during this period than in the winter. The structures and seasonal variability of composites of CHL" shown in Figure 5 are qualitatively very similar to the original $\mathrm{CHL}^{\prime}$ anomalies, see Figure A1.

[42] The dipole structure of composite averages of eddy $\mathrm{CHL}^{\prime \prime}$ during November through April is very similar to the dipole structures observed in global composites of CHL anomalies in midlatitude eddies of both polarities [Chelton et al., 2011b]. These structures arise from horizontal advection of the surrounding large-scale CHL field by the rotational velocities in eddies [Chelton et al., 2011b]. In the absence of an observed CHL response to eddy-induced Ekman pumping, the advection of CHL around eddies appears to dominate the composites of CHL" as a result of the rotational velocities of the eddies and the presence of a background CHL gradient the SIO (Figure 1c).

[43] The wintertime (May to October) averaged composites of $\mathrm{CHL}^{\prime \prime}$ and eddy-induced Ekman pumping are shown in Figure 6a. Composites of $C^{\prime \prime}$ phyto for the same eddies (Figure $6 \mathrm{~b}$ ) are distinctly different from $\mathrm{CHL}^{\prime \prime}$. 


\section{Composite Averages of Rotated and Normalized CHL" Anomalies}

anticyclones
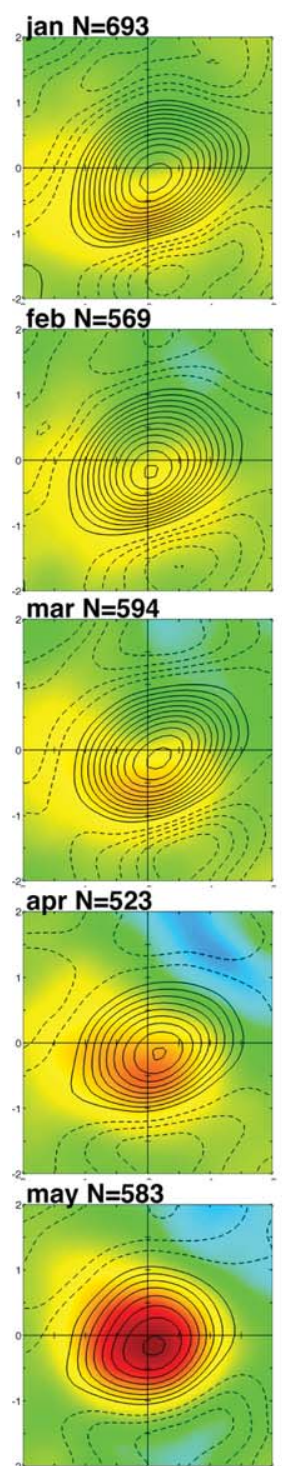

jun $\mathbf{N}=595$

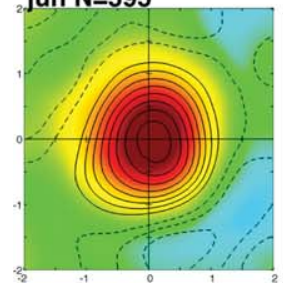

cyclones
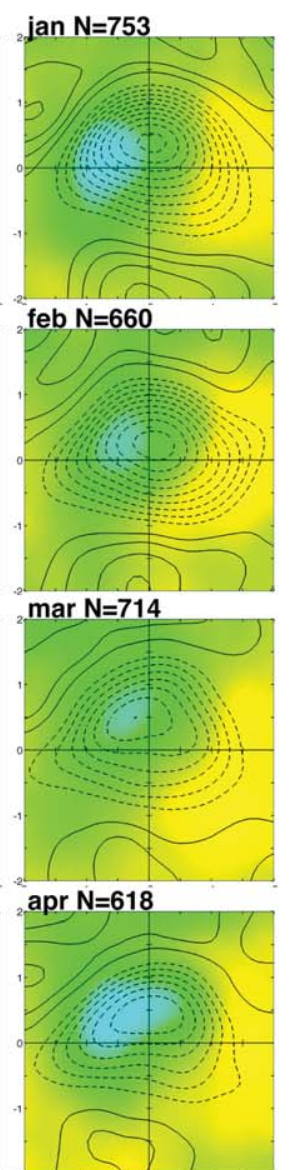

may $\mathrm{N}=675$
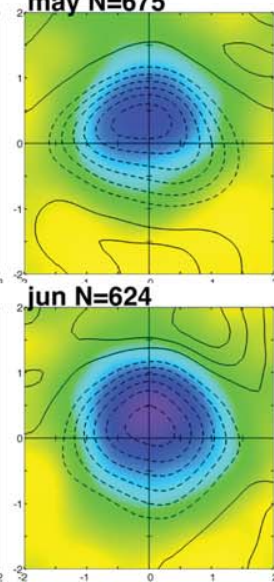

anticyclones

cyclones
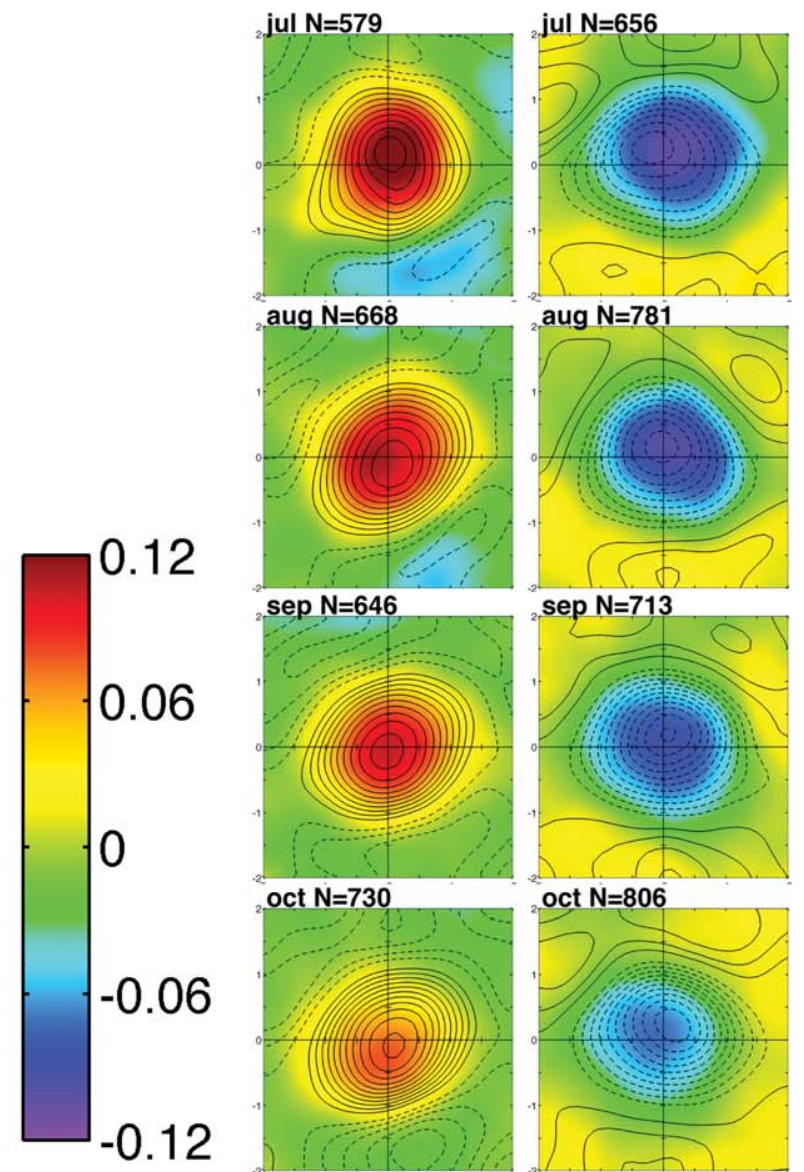

oct $\mathrm{N}=806$

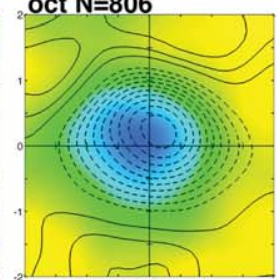

$-0.12$

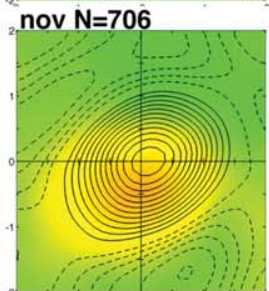

${ }_{2} \operatorname{dec} \hat{N}=68 \hat{1}$

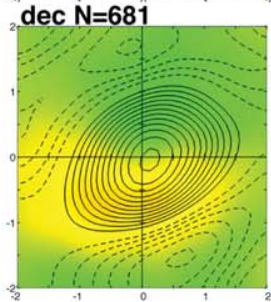

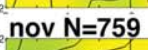

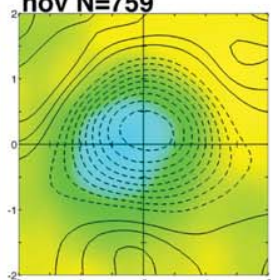

$\operatorname{dec} \mathrm{N}=734$

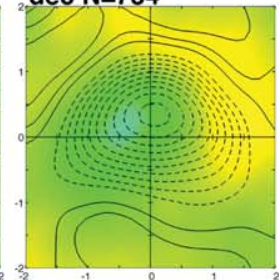

Figure 5. Monthly composite averages of rotated and normalized overlaid with contours of eddy-induced Ekman pumping velocity. See section 2.3 for a description of how normalized are computed and section 2.4 for a description of how the individual eddy realizations are rotated to align the background wind direction to a polar angle of $0^{\circ}$. The $x$ and $y$ coordinates of the composite averages are normalized by the eddy scale $L_{s}$. Contour interval of Ekman pumping velocity is $1 \mathrm{~cm}^{\text {day }}{ }^{-1}$ and negative velocities are shown as dashed curves. The left and right plots of each column of paired panels are for anticyclones and cyclones, respectively, for January (top left pair of plots) and progressing forward in time to December in the bottom right pair of plots. The title of each plot includes the number of eddy realizations used in the composite. 
May Through October Composite Averages

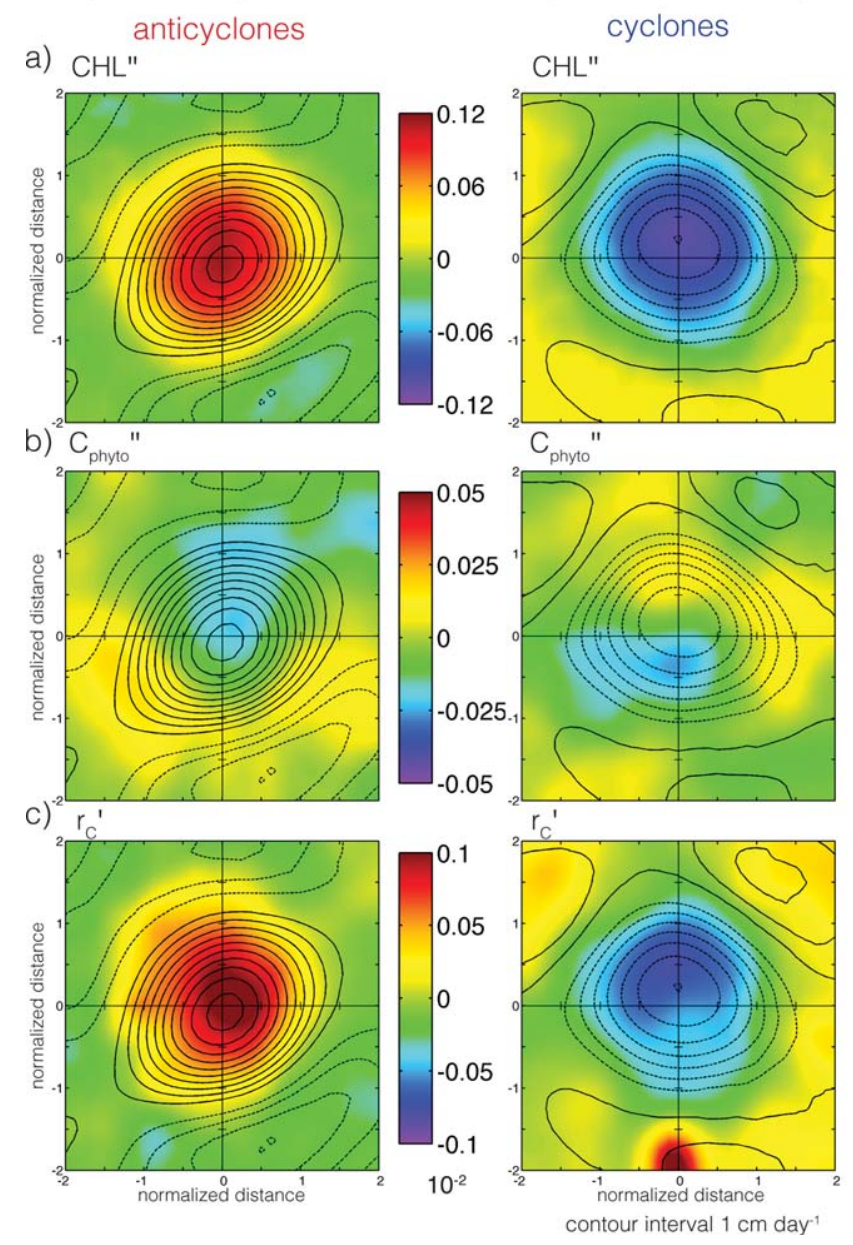

Figure 6. Composite averages for (left) anticyclonic and (right) cyclonic SIO eddies during the winter (May through October): (a) $\mathrm{CHL}^{\prime \prime}$, (b) $C^{\prime \prime}$ phyto and (c) $r_{C}^{\prime}$. As in Figures 2 and 5, the $x$ and $y$ coordinates of the composite averages are normalized by the eddy radius scale $L_{s}$. The contours overlaid on each plot are the May through October composite mean Ekman pumping velocities with a contour interval of $1 \mathrm{~cm}$ day $^{-1}$ with negative velocities are shown as dashed lines.

Anticyclones are characterized as having positive $C^{\prime \prime}$ phyto along the southwestern edge of the westward-propagating eddies with negative $C^{\prime \prime}$ phyto offset to the north-northeast of the eddy centroids. This structure is similar to the abovenoted dipole signature of rotational advection [Chelton et al., 2011b]. The spatial pattern of $C^{\prime \prime}$ phyto is consistent with the background southward gradient of $C_{\text {phyto }}$ found in this region (Figure 1c). The same azimuthal advection of the ambient $C_{\text {phyto }}$ field around the periphery is observed in SIO cyclones during the winter, inferred from the dipole structure of wintertime $C^{\prime \prime}$ phyto.

[44] As discussed in section 2.3, anomalies of the ratio $r_{C}$ are used here as a proxy for the phytoplankton growth rate, $\mu$. Positive and negative $r_{C}^{\prime}$ are observed in the cores of anticyclones and cyclones, respectively (Figure 6c). These $r_{C}^{\prime}$ ratios are restricted to the inner cores of the eddies within radii of about $L_{s}$ from the eddy centroids. The maximum values of $r_{C}^{\prime}$ in anticyclones are closely collocated with the maximum eddy-induced Ekman pumping. To the extent that this ratio is a good proxy for $\mu$, this suggests that the growth rates of the photoautotrophic communities trapped within anticyclones are at least partly sustained by the Ekman pumping within the cores of the SIO eddies. The high CHL anomalies in the left plot of Figure $6 \mathrm{a}$ are thus indicative of increased growth rate rather than photoacclimation. This is discussed in more detail in the next section.

[45] The reverse pattern is observed for cyclones, within which the negative values of $r_{C}^{\prime}$ are closely collocated with the maximum Ekman downwelling (Figure 6c, right). This suggests that continuous downwelling impedes any upward nutrient flux into the euphotic zone, thus reducing CHL and $\mu$.

[46] Anticyclonic eddies formed from the pinching off of meanders of poleward-flowing eastern boundary currents preferentially entrain continental shelf water, which seeds their interiors with productive (eutrophic) ecosystems [Pearce and Griffiths, 1991]. On the other hand, cyclones that form in the Leeuwin current entrain water from offshore during formation, resulting in trapped fluid that is low in nutrients and CHL. To investigate if the composite averages of CHL" within SIO eddies are dominated by the initial entrainment of CHL during eddy formation, and not a response to eddy-induced Ekman pumping, we constructed time series of CHL" in eddy interiors for all SIO eddies observed during May to October. The CHL" signals persist within the cores of SIO eddies for $\sim 1$ year (Figure 7). Nutrients entrained and trapped during eddy formation would be exhausted by the photoautotrophic community in the first few weeks of an eddy's lifetime, suggesting that eddy-induced Ekman pumping could sustain the observed CHL".

[47] The ambient CHL field in the SIO varies seasonally with maximum values observed during the Austral winter (Figure 8a). Likewise, the magnitudes of $\mathrm{CHL}^{\prime}$ also have

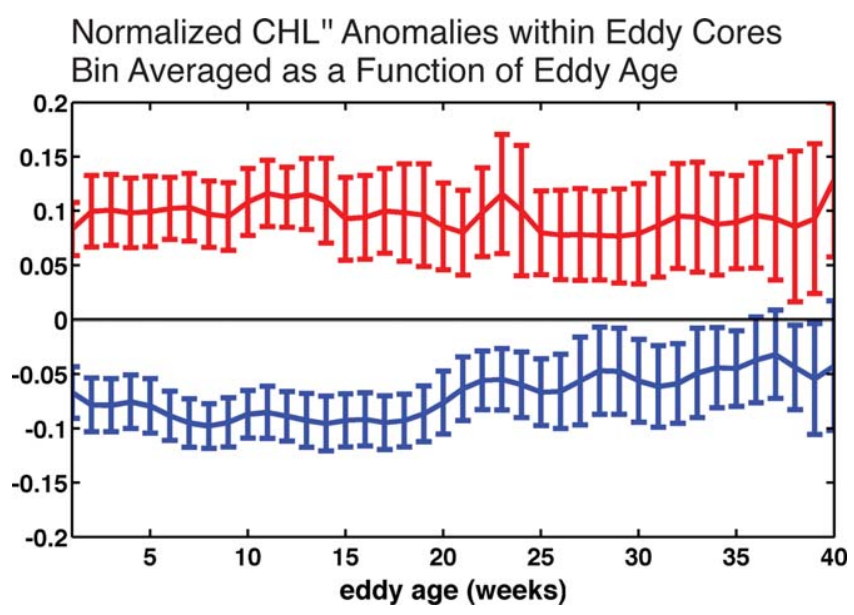

Figure 7. CHL" anomalies bin averaged as a function of eddy age within $0.5 L_{S}$ of the centroids of cyclones and anticyclones, shown in blue and red, respectively, from May through October. Error bars show the 95\% confidence interval of the mean, computed as described in Appendix C. 
a) Background $\mathrm{CHL}$ Averaged Over Study Region

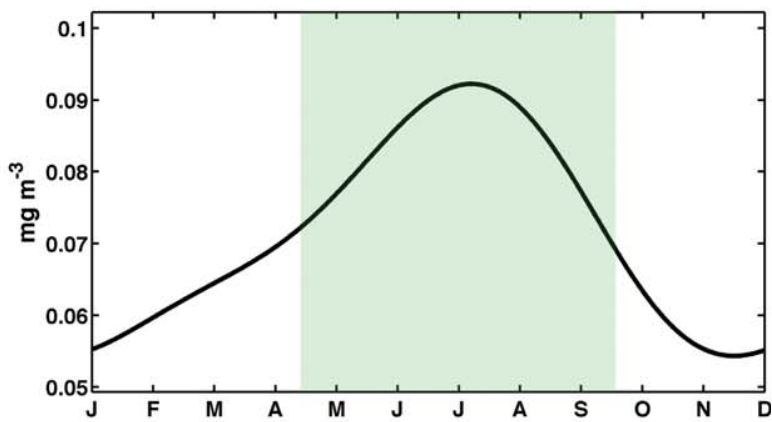

b) $\mathrm{CHL}$ ' Within Eddies

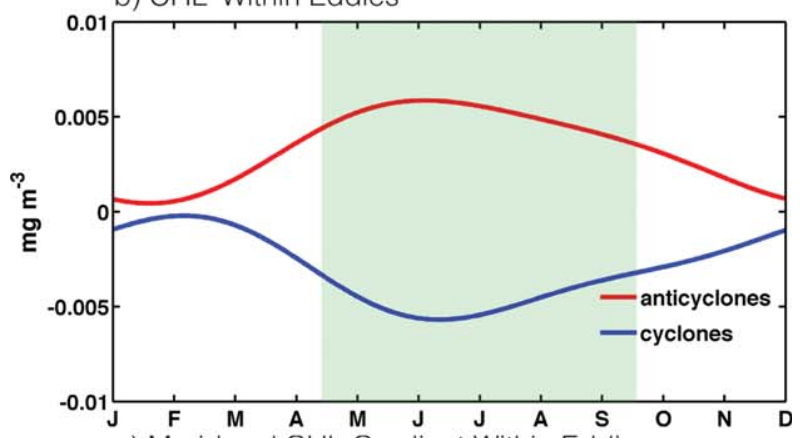

c) Meridonal $\mathrm{CHL}$ Gradient Within Eddies

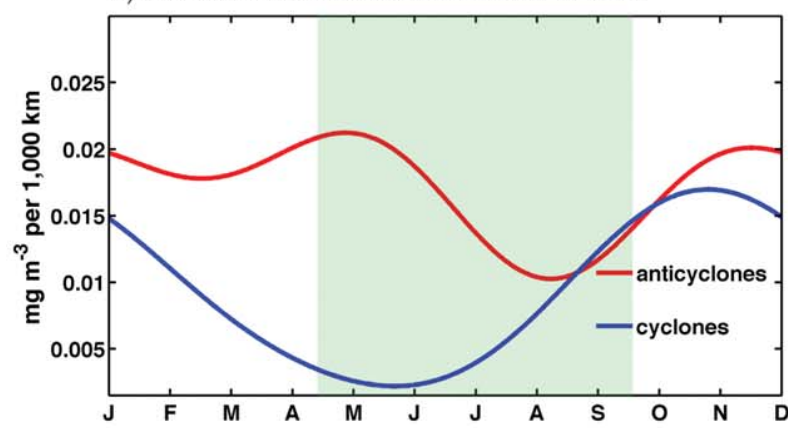

d) Mixed Layer Depth and $\mathrm{k}_{d}^{-1}$ Within Eddies

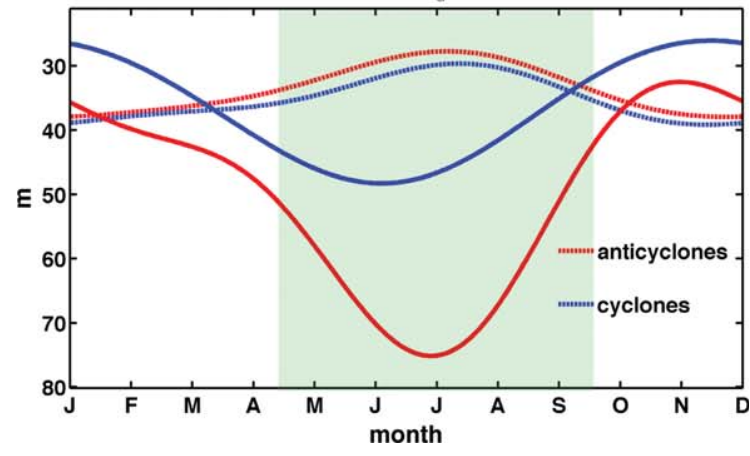

Figure 8. The seasonal cycle is calculated by regression of the annual cycle and its first harmonic of (a) The background CHL averaged over the study domain, (b) $\mathrm{CHL}^{\prime}$ from SeaWiFS within eddy interiors for anticyclones and cyclones shown as red and blue curves, respectively, (c) the meridional component of the background CHL gradient from SeaWiFS within eddy interiors, and (d) MLD estimated from Argo float profiles within eddy interiors (solid curve) and the first optical depth at $490 \mathrm{~nm}$ (computed as $k_{d}^{-1}$ ). The green overlay on all panels represents the wintertime when CHL anomalies are collocated with maximum eddy-induced Ekman upwelling in the interiors of SIO anticyclones (see Figures 5 and 6). the same seasonality as a result of the high-pass filtering (Figure 8b). The seasonal appearance and disappearance of the dipole structures in the $\mathrm{CHL}^{\prime \prime}$ composites in Figure 5 suggests that these structures might be the result of seasonal variability of the background CHL field. To investigate the influence of the background CHL gradient on the observed composites of $\mathrm{CHL}^{\prime \prime}$ and $r_{C}^{\prime}$, the CHL fields were smoothed to attenuate variability with periods shorter than 200 days and smaller than $6^{\circ} \times 6^{\circ}$. The 200 day filter halfpower cutoff was used to remove eddy contributions to temporal variability of the CHL fields. The magnitude of the northward component of the gradient of the resulting smoothed CHL in anticyclones has a bimodal seasonal cycle with peaks in both May and December (red line in Figure $8 \mathrm{c}$ ). In cyclones, there is a minimum in June and a maximum in November (blue line in Figure 8c). These variations are, to some degree, in phase with what is expected from the $\mathrm{CHL}^{\prime \prime}$ composites. In particular, the dipole structure of CHL" in anticyclones is clearest from November to April (Figure 5) when the northward background CHL gradient is strong (Figure 8c). However, the maximum of the meridional gradient of the background CHL in May in the anticyclones occurs when the $\mathrm{CHL}^{\prime \prime}$ distribution has a monopole structure that is indicative of response to eddyinduced Ekman pumping. Thus, while the strength of the ambient CHL gradient is likely a factor in determining when the dipole structure is apparent, it is evidently not the only factor controlling the $\mathrm{CHL}^{\prime \prime}$ distribution in SIO eddies.

[48] To investigate whether the seasonal variations of the CHL" distribution within eddies and their relationship to Ekman pumping arise from processes occurring below the sea surface, we investigated the seasonality of MLD (computed as described in section 2.4) and optical depth, defined to be the inverse of the diffuse attenuation coefficient at $490 \mathrm{~nm}, K_{d}^{-1}$. The observed seasonal variability of $\mathrm{CHL}^{\prime}$ (Figure $8 \mathrm{~b}$ ) varies approximately in phase with the seasonal variability of the MLD in cyclones and approximately out of phase in anticyclones (Figure $8 \mathrm{~d}$, solid curves). The optical depth at $490 \mathrm{~nm}$ varies approximately in phase with $\mathrm{CHL}^{\prime}$ in anticyclones and out of phase with $\mathrm{CHL}^{\prime}$ in cyclones (Figure 8d, dashed curves). The wintertime maximum MLD (June, July, and August) reaches a depth of $75 \mathrm{~m}$ in anticyclones and $45 \mathrm{~m}$ in cyclones, both of which are deeper than the $\sim 30 \mathrm{~m}$ optical depth during this time. During the summer, the mixed layer shoals in SIO eddies and becomes shallower than the optical depth. During this time, CHL is expected to be maximum near the base of the euphtoic zone, at a depth of $\sim 100 \mathrm{~m}$ [Hanson et al., 2007], deeper than both the mixed layer and optical depth.

[49] From the analysis of SIO eddies presented above, wintertime $\mathrm{CHL}^{\prime \prime}$ appear to be related to eddy-induced Ekman pumping. The monopoles of $\mathrm{CHL}^{\prime \prime}$ in SIO eddies disappear from November to April, suggesting that other mechanisms likely dominate the response of near-surface CHL during the summer. Changes in stratification and the depth to which CHL can be observed by satellites likely also play a role in the observed seasonal variations of $\mathrm{CHL}^{\prime \prime}$. The relative importance of all of these mechanisms are evaluated in the discussion. 


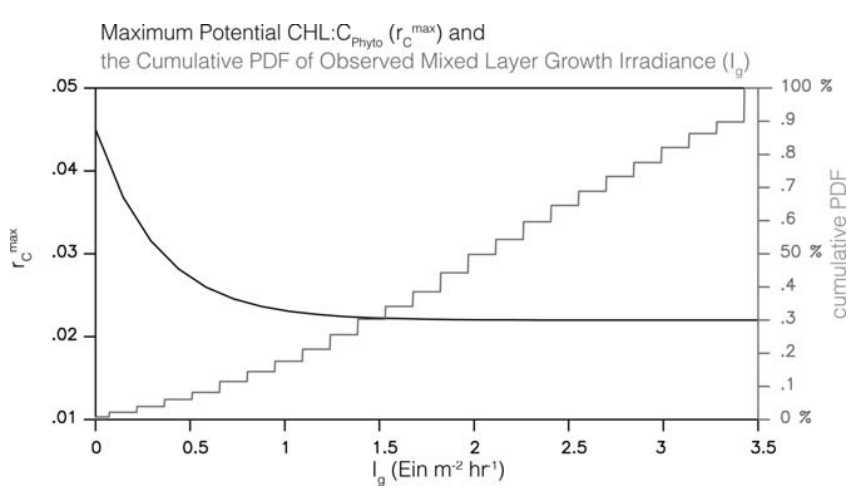

Figure 9. Maximum potential CHL-to- $C_{\text {phyto }}$ ratio, $r_{C}^{\max }$, as defined by equation (9) as a function of mean mixed layer growth irradiance $\left(I_{g}\right)$ (smooth curve) and the cumulative probability density function of observed $I_{g}$ as defined by equation (10) within the cores of SIO eddies (the stepped gray line).

\section{Discussion}

[50] The analyses in section 3 showed that during the Austral winter, anomalously high CHL within anticyclones is coincident with Ekman upwelling and anomalously low CHL within cyclones is coincident with Ekman downwelling. These responses of CHL to eddy-induced Ekman pumping occur only during the wintertime, despite the fact that eddy-induced Ekman pumping remains strong throughout the year.

[51] During late fall and winter, $\mathrm{CHL}^{\prime \prime}$ is greatly increased in anticyclones in the region of maximum eddyinduced Ekman pumping (Figure 5). This is also the time of year of deepest mixed layers and lower solar insolation. The association of increased $\mathrm{CHL}^{\prime \prime}$ and $r_{C}^{\prime}$ with deeper mixing (Figures 6 and 8) suggests two possible connections: (1) the phytoplankton community increases its photosynthetic pigment concentration to acclimate to the decreased average irradiance in the deepened mixed layer (photoacclimation) and (2) the deep winter mixed layer acts to homogenize CHL within the first optical depth, allowing for a CHL response to eddy-induced Ekman pumping to be observed by satellites. These two hypotheses are investigated here.

[52] Consider first the hypothesis that seasonal variability of CHL" in anticyclones is the result of photoacclimation. As the light available for photosynthesis is reduced in winter and the mixed layer deepens, the phytoplankton community is expected to respond by increasing intracellular CHL in order to absorb enough photons for photosynthesis. This process of photoacclimation can increase observed CHL relative to $C_{\text {phyto }}$. This is accounted for in the estimation of the phytoplankton growth rate $\mu$ by inclusion of the nutrient and temperature dependence of the maximum CHL-to- $C_{\text {phyto }}$ ratio parameter $r_{C}^{\max }$ in equation (8). As shown in Figure $9, r_{C}^{\max }$ decreases exponentially to a constant of $\sim 0.2$ with increasing $I_{g}$. This effect of photoacclimation is most pronounced for $I_{g} \leq 0.5 \mathrm{Ein} \mathrm{m}^{-2} \mathrm{hr}^{-1}$. When $I_{g} \geq 1$ Ein $^{-2} \mathrm{hr}^{-1}, r_{C}^{\max }$ is nearly invariant. Estimates of $I_{g}$ derived from equation (10) based on MLD from Argo profiles in SIO eddy cores show that $18 \%$ of the $I_{g}$ values fall in the range where $I_{g} \leq 1 \mathrm{Ein} \mathrm{m}^{-2} \mathrm{hr}^{-1}$. Only

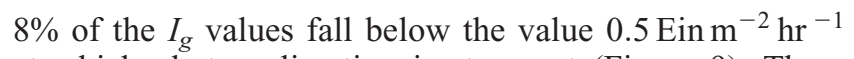
at which photoacclimation is strongest (Figure 9). These results indicate that phytoplankton communities in these eddies are only rarely light limited, a conclusion that is in agreement with in situ observations reported by Thompson et al. [2007]. Consequently, we can interpret the $r_{C}$ variability as predominantly indicative of changes in phytoplankton growth rate $\mu$ and investigate its variability in the SIO during the summer and winter.

[53] During the summer, when the composites of SIO anticyclones have dipole structures that are symptomatic of horizontal advection of the ambient CHL field around their peripheries, the average $\mu$ within anticyclones is 0.54 day $^{-1}$, which is not significantly different from the average of 0.55 day $^{-1}$ within cyclones (Table 1). During winter, however, when CHL and $r_{C}$ respond to eddy-induced Ekman pumping (Figure 6), the average $\mu$ within anticyclones is 0.66 day $^{-1}$, which is significantly larger ( $\alpha=0.05,95 \%$ confidence) than the average $\mu$ of 0.61 day $^{-1}$ within cyclones (Table 1).

[54] During winter, energetic mixing homogenizes CHL throughout the mixed layer permitting satellite observations of a response to eddy-induced Ekman pumping in anticyclones. On the other hand, during the summer surface mixing is weak so a CHL response to eddy induced Ekman pumping would occur near the base of the euphotic zone, which is deeper than the first optical depth and thus not observed by satellites. Preliminary results from an Argo float equipped with a bio-optical package deployed in an SIO anticyclone support this idea. The float was deployed near $27^{\circ} \mathrm{S}, 105^{\circ} \mathrm{E}$ on 31 August 2012 in an anticyclonic mesoscale eddy. The float remained within the anticyclone until 17 December 2012. Chlorophyll fluorescence was nearly uniform in the upper $\sim 120$ m from August until the end of October 2012, when the mixed layer shallowed and chlorophyll fluorescence was limited to below $100 \mathrm{~m}$ in a clear deep CHL maximum (P. G. Strutton, manuscript in preparation, 2013).

[55] Other mechanisms described in the literature that could sustain phytoplankton populations in anticyclonic eddies are not able to reproduce the observed CHL and $r_{C}$ maxima and minima in the cores of anticyclonic and cyclonic eddies observed in the SIO. For example, Mahadevan et al. [2008] proposed that nonlinear Ekman pumping, resulting from the inclusion of momentum advection in the formulation of Ekman pumping, could explain the enhanced primary production rates observed in the interior

Table 1. Phytoplankton Growth Rate $(\mu)$ Within Anticyclonic and Cyclonic South Indian Ocean Eddies ${ }^{\mathrm{a}}$

\begin{tabular}{lccccc}
\hline & \multicolumn{2}{c}{ Summer } & & \multicolumn{2}{c}{ Winter } \\
\cline { 2 - 3 } \cline { 5 - 6 } & Mean & C.I. & & Mean & C.I. \\
\hline Anticyclones & 0.54 day $^{-1}$ & \pm 0.016 & & 0.66 day $^{-1}$ & \pm 0.024 \\
Cyclones & 0.55 day $^{-1}$ & \pm 0.016 & & 0.61 day $^{-1}$ & \pm 0.023
\end{tabular}

${ }^{\text {a }}$ For details on how $\mu$ is estimated see section 2.6. The $95 \%$ confidence intervals (C.I.) are defined as $\pm \sigma(\mu) q_{t}(0.025, N-1) / \sqrt{N}$, where $\sigma(\mu)$ is the standard deviation of the phytoplankton growth rate $(\mu)$ estimates within the bounds of eddies of either polarity and $q_{t}(0.025, N-1)$ is the 2.5 percentage point of the Students $t$ distribution with $N-1$ degrees of freedom. 
of a mode-type anticyclone in the North Atlantic. In contrast to the observed wintertime monopole structure centered on the cores of SIO anticyclones, nonlinear Ekman pumping consists of a dipole of opposing upwelling and downwelling along the peripheries on opposite sides of mesoscale ocean eddies [McGillicuddy et al., 2008; Gaube, 2012]. As argued by McGillicuddy et al. [2008], the net effect of the alternating nonlinear Ekman upwelling and downwelling experienced by a parcel of water advected around the periphery of an eddy is small. An advected parcel that is upwelled into the euphotic zone in the region of nonlinear Ekman upwelling spends only a limited amount of time in the euphotic zone. More fundamentally, nonlinear Ekman pumping would enhance CHL and the $r_{C}$ along only one side of the eddy periphery, rather than centered on the core of the eddy as is observed in the SIO during winter (Figures 5 and 6).

[56] An additional mechanism by which CHL can be enhanced in anticyclones was proposed by Lévy and Klein [2004], where a coupled bio/physical numerical simulation of an eddying field forced by large-scale vertical and horizontal density gradients was conducted. The upwelling of nutrients was observed in anticyclonic vorticity regions as a result of the physical flow field locally organizing the horizontal and vertical velocities during the adjustment of the density field such that a thermal-wind balance is maintained in the presence of horizontal and vertical density gradients [Klein et al., 1998; Lévy and Klein, 2004]. Their results suggest that elevated phytoplankton biomass in anticyclones can result from the advection of phytoplankton produced in regions of upwelling along anticyclone vorticity fronts into the interior of anticyclonic eddies observed in the SIO. Although this mechanism could result in enhanced CHL within anticyclones, we are not able to resolve these spatial scales.

[57] From satellite observations alone, it is not possible to rigorously test weather the observed phytoplankton response within SIO mesoscale eddies results from the eddy-induced Ekman pumping or the afore-mentioned generation of enhanced CHL along anticyclonic vorticity fronts or submesoscale regions of upwelling. Further high resolution in situ studies are needed to elucidate why a phytoplankton response to eddy-induced Ekman pumping is only observed during the winter in SIO eddies and the relative importance of submesoscale vertical motions on phytoplankton concentrations.

[58] While many of the eddies selected for this study form in the Leeuwin Current, some appear to originate far offshore (Figures $3 \mathrm{a}$ and $\mathrm{b}$ ). An eddy identified by the automated eddy tracking procedure can disappear and reappear weeks or even months later, depending on the evolving structures of the eddy from one time step to the next and errors in the SSH fields because of the space-time distribution of the altimeter data. Although relatively uncommon, examples of eddies that are "lost" and subsequently rediscovered by the eddy tracking procedure were found by studying animations of SSH in the SIO and comparing the tracks derived from the automated procedure to eddies tracked visually. Whenever temporary loss of a tracked eddy occurred, it was because of temporal irregularities in the characteristics of the eddy along its trajectory. As a result of the inability of the automated procedure to bridge across these irregularities, some of the eddies formed offshore of the Leeuwin Current actually originated in the Leeuwin Current.

[59] The number of eddies that the tracking procedure identified as forming offshore is, however, too large to be entirely accounted for in this manner. Many of these eddies must truly form in the open ocean, presumably from baroclinic instabilities [e.g., Smith, 2007]. It is shown in Appen$\operatorname{dix} B$ that these open-ocean anticyclones have locally elevated phytoplankton (and presumably nutrient concentrations) similar to what is observed in eddies that originate in the Leeuwin Current. Anticyclones that form offshore are similarly preconditioned to have high initial CHL and a response to eddy-induced Ekman pumping because of the northward gradient of background CHL and the generally eastward upper ocean currents (see Appendix B). Enhanced CHL in anticyclones formed offshore (see Figure B7) is yet another line of evidence suggesting the importance of eddy-induced Ekman pumping sustaining positive $\mathrm{CHL}^{\prime \prime}$ in SIO anticyclones.

[60] It is perhaps perplexing that an accumulation of biomass (i.e., an increase of $C_{\text {phyto }}$ ) is not observed in association with the increase of CHL in the cores of anticyclones (Figure 6b). In oligotrophic regions such as the SIO, however, a decoupling of $C_{\text {phyto }}$ from CHL is a common occurrence [Behrenfeld et al., 2005]. The primary reason for this decoupling is presumed to be that the zooplankton grazing community maintains the phytoplankton stock at a relatively constant level, but this predator-prey matching does not track physiological changes in intracellular chlorophyll. In other words, an increase in nutrients within an eddy will increase phytoplankton growth rates $\mu$, and thus $r_{C}$. This increase in $r_{C}$ results from increased CHL relative to $C_{\text {phyto }}$. Any associated increase in biomass $C_{\text {phyto }}$ is rapidly responded to by an increase in grazing pressure, thus resulting in the lack of positive $C^{\prime \prime}$ phyto anomalies, even though $\mu$, $r_{C}$, and CHL are increased in anticyclones, relative to the background.

[61] Observations by Paterson et al. [2007] of the grazing of phytoplankton by zooplankton in a pair of Leeuwin Current eddies of opposite polarities support this interpretation of the wintertime relationship between $C_{\text {phyto }}$ and CHL. The anticyclonic eddy contained significantly more zooplankton biomass than the cyclone. The grazer community was dominated by large dinoflagellates that graze upon diatoms. Estimates of the phytoplankton mortality from grazing in both of the eddies suggested that grazing rates were sufficient to account for all of the primary production measured in the eddies. A tight coupling between phytoplankton biomass and the grazer community could thus explain why an accumulation of biomass is not observed in the composites of $C^{\prime \prime}{ }_{\text {phyto }}$ in Figure $6 \mathrm{~b}$, even in the presence of high $\mu$ (Figure 6c).

\section{Conclusions}

[62] Satellite observations have shown that mesoscale ocean eddies in the SIO are highly nonlinear [Chelton et al., 2011a]. Trapped fluid can therefore be found within the cores of these eddies, limiting mixing with the surrounding water [e.g., McWilliams and Flierl, 1979; Early et al., 2011]. The cores of the eddies also coincide with the 
regions of the highest surface current-induced curl of the surface stress with sign opposite that of the vorticity of the eddies, resulting in Ekman pumping velocities that are of order $10 \mathrm{~cm}$ day $^{-1}$. Evidence was presented here that the Ekman upwelling in anticyclonic SIO eddies could sustain enhanced CHL concentrations during the winter when compared to the oligotrophic waters that surround them.

[63] It appears that a critically important feature for Ekman upwelling to sustain the phytoplankton within an anticyclone is that a high concentration of phytoplankton and nutrients must be entrained into the eddy during formation. In this regard, the anticyclones in the SIO are unusual. Many of them form in the Leeuwin Current, which is unique among eastern boundary currents in that the flow is poleward. Leeuwin Current anticyclones preferentially entrain water from the continental shelf that is high in both phytoplankton biomass and nutrients. In all other eastern boundary currents, the highly productive shelf water is entrained into cyclones during formation, which subsequently develop eddy-induced Ekman downwelling. Anticyclones that form offshore are similarly preconditioned to have high initial CHL because of the weak northward gradient of background CHL and the generally eastward upper ocean currents (see Appendix B).

[64] The positive CHL anomalies in anticyclones formed in the Leeuwin Current can be sustained by the relatively small eddy-induced Ekman pumping anomalies of $\sim 10 \mathrm{~cm}$ $d a y^{-1}$ because the photoautotrophic ecosystems trapped within these eddies are expected to quickly adapt to low ambient nutrient concentrations. Anticyclones propagate into the open ocean and the very high nutrient concentrations trapped during formation are quickly depleted. This change in the nutrient field can result in changes in the phytoplankton community composition. After sufficient time following eddy formation, the phytoplankton community trapped within these anticyclones will be dominated by species that are adapted to low nutrient concentrations. These efficient photoautotrophic ecosystems can thus generate an observable CHL response to the small, yet persistent, Ekman upwelling of new nutrients into the cores of the anticyclones. In the case of anticyclones formed offshore, the photoautotrophic community entrained during formation are already adapted to low ambient nutrient concentrations, thus a response to eddy-induced Ekman pumping can be observed.

[65] The anomalies of CHL and the CHL-to- $C_{\text {phyto }}$ ratio $r_{C}$ in the interiors of the anticyclones exhibit a strong seasonality with the highest $\mathrm{CHL}$ and $r_{C}$ values occurring during the Austral winter. Based on measurements of stratification from autonomous Argo floats and the depth to which satellite can estimate CHL, evidence was presented that suggests that elevated CHL driven by Ekman upwelling in anticyclones is observed by satellites only during the winter because this is the only time of the year that the mixed layer is sufficiently deep to transport CHL to the surface.

[66] Available in situ and satellite observations are not sufficient to rigorously test if the observed $\mathrm{CHL}^{\prime \prime}$ within mesoscale eddies of the SIO are predominately generated by eddy-induced Ekman pumping. A quantification of the relative importance of the mechanisms generating the observed $\mathrm{CHL}^{\prime \prime}$ in these eddies need to be further examined with coupled ecosystem models and dedicated process studies.

\section{Appendix A: To Log or Not To Log?}

[67] When working with bio-optical observations such as CHL or $C_{\text {phyto }}$, the distribution of the observations must be considered before spatially and temporally filtering, constructing averages, calculating statistical properties, or testing hypotheses. Satellite-based estimates of bio-optical properties are usually based on log-transformed CHL [e.g., Uz et al., 2001; Cipollini et al., 2001; Doney et al., 2003; Uz and Yoder, 2004; Killworth et al., 2004; Siegel et al., 2007; Gutknecht et al., 2010; Siegel et al., 2011; Chelton et al., 2011b]. This tradition appears to be traceable to an

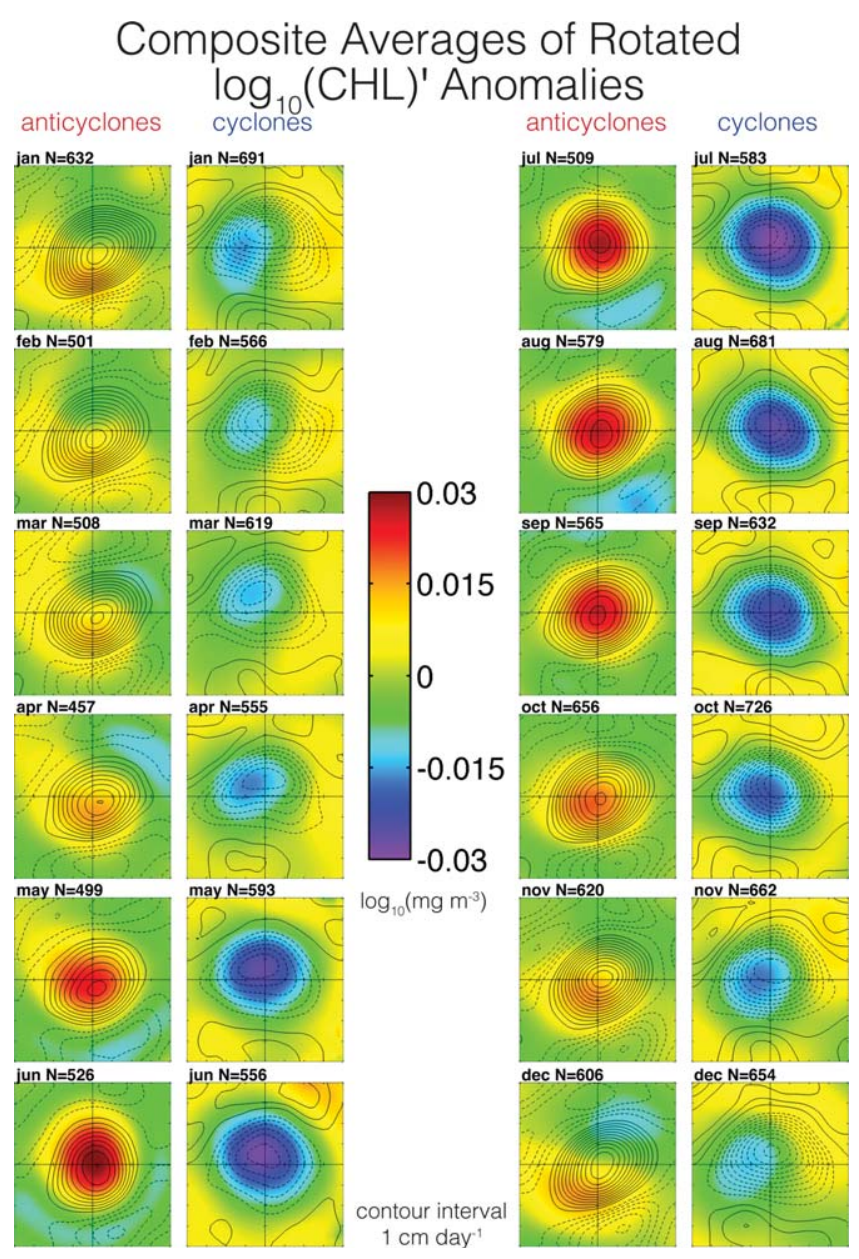

Figure A1. Similar to Figure 5, except monthly composite averages of rotated $\left[\log _{10}(\mathrm{CHL})\right]^{\prime}$ anomalies (not normalized) overlaid with contours of eddy-induced Ekman pumping. As in Figure 5, the $x$ and $y$ coordinates of the composite averages are normalized by the eddy scale $L_{s}$. Contour interval of Ekman pumping velocity is $1 \mathrm{~cm}^{\text {day }}{ }^{-1}$ and negative velocities are shown as dashed curves. The left and right plots of each column of paired panels are for anticyclones and cyclones, respectively, for January (top left pair of plots) and progressing forward in time to December in the bottom right pair of plots. The title of each plot includes the number of eddy realizations used in the composite. 
early analysis of in situ observations and individual scenes from the Costal Zone Color Scanner by Campbell [1995]. While less common, a number of studies have investigated nonlog-transformed CHL [e.g., Machu et al., 1999; Charria et al., 2003; McClain et al., 2004; Charria et al., 2006, 2008].

[68] To assess whether the conclusions of this study are dependent on our choice in sections 3 and 4 of analyzing anomalies of the raw CHL data, we repeated the analysis in section 3 based on anomalies calculated from the $\log _{10}$ transformed CHL data. The CHL observations were first $\log _{10}$ transformed and then smoothed in space as described in section 2.3 to calculate the large-scale $\log _{10}$ transformed CHL, which we denote as $\overline{\log _{10}(\mathrm{CHL})}$. The anomaly $\log _{10}$ transformed fields were then defined by

$$
\left[\log _{10}(\mathrm{CHL})\right]^{\prime}=\log _{10}(\mathrm{CHL})-\overline{\log _{10}(\mathrm{CHL})} .
$$

[69] We then constructed composite averages of the $\left[\log _{10}(\mathrm{CHL})\right]^{\prime}$ anomalies in units of $\log _{10}\left(\mathrm{mg} \mathrm{m}^{-3}\right)$ rotated to align the background wind direction to a polar angle of $0^{\circ}$ (Figure A1). The seasonal variability of the structure of $\left[\log _{10}(\mathrm{CHL})\right]^{\prime}$ in the interiors of mesoscale SIO eddies is essentially the same as that of $\mathrm{CHL}^{\prime \prime}$ shown in Figure 5. The same summertime dipole pattern in anticyclones is observed in the composites with and without $\log _{10}$ transformation. Likewise, the wintertime anomalies in the anticyclones with and without the $\log _{10}$ transform consist of monopole structures centered within the regions of strong Ekman upwelling. Moreover, the spatial structure of the composites for cyclones is also essentially the same with and without the $\log _{10}$ transform.

[71] It is thus apparent that the conclusion of this study are insensitive to whether or not the CHL data are log transformed. Investigation of non- $\log _{10}$ transformed CHL anomalies has merit as it allows for comparisons of the results presented in this study to future in situ or coupled physical/biological modeling studies in the measured units of $\mathrm{CHL}$.

\section{Appendix B: Eddies Originating in the Leeuwin Current Versus the Open Ocean}

[72] Our interest was initially in the CHL content of eddies that form in the Leeuwin current, which have been studied extensively [Cresswell, 1977; Legeckis and Cresswell, 1981; Andrews, 1983; Batteen and Rutherford, 1990; Fang and Morrow, 2003; Batteen et al., 2007; Feng et al., 2007; Gaughan, 2007; Greenwood et al., 2007; Holl et al., 2007; Moore et al., 2007; Muhling et al., 2007; Paterson et al., 2008; Strzelecki et al., 2007; Thompson et al., 2007; Waite et al., 2007a, 2007b, 2007c]. To increase the number of eddy realizations, the analysis in sections 3 and 4 was based on composites constructed from all of the eddies that formed within the region enclosed by the 0.2 cross correlation contour in Figure 1d. This tripled the number of longlived eddies compared with the number formed in the Leeuwin Current.

[73] To investigate whether the conclusions of sections 3 and 4 are applicable to the Leeuwin Current eddies, we consider in this appendix only the eddies that the automated eddy tracking procedure of Chelton et al. [2011a] identified
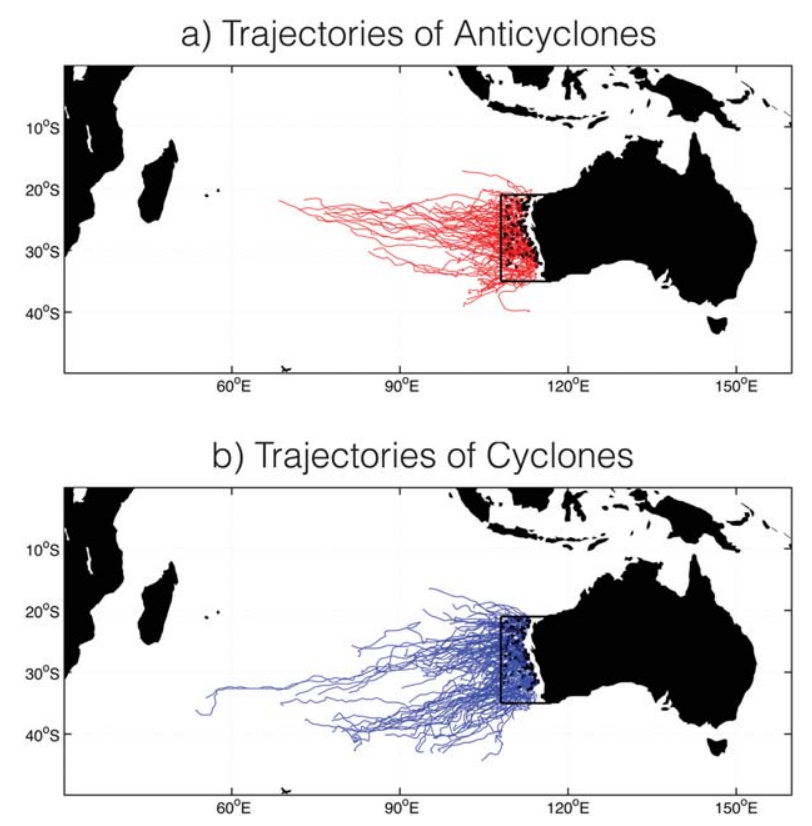

Figure B1. Trajectories of the (a) anticyclonic and (b) cyclonic eddies originating in the Leeuwin Current, defined as the region $35^{\circ} \mathrm{S}-21^{\circ} \mathrm{S}$ and east of $108^{\circ} \mathrm{E}$ (enclosed by the back box). The start location of each eddy is marked with a black circle.

as having formed in the Leeuwin Current, defined here to be eddies that originated in the region $35^{\circ} \mathrm{S}-21^{\circ} \mathrm{S}$ and east of $108^{\circ} \mathrm{E}$ (Figure B1). This resulted in 142 cyclonic and 108 anticyclonic eddies with lifetimes of 12 weeks and longer consisting of 5840 and 3522 weekly realizations, respectively, over the 9 year study period (January 2001 through November 2009). For comparison, the subset of eddies analyzed in sections 3 and 4 consisted of about a factor-of-3 more long-lived eddies (474 cyclones and 382 anticyclones, consisting of 9507 and 8314 weekly realizations, respectively).

[74] The average amplitudes of the Leeuwin Current eddies are $11.1 \mathrm{~cm}$ and $10.7 \mathrm{~cm}$ for cyclones and anticyclones, respectively, with average radial scales $L_{s}$ of $81 \mathrm{~km}$ and $96 \mathrm{~km}$ (Figures B2a and B2b). Although cyclones on average are somewhat larger in amplitude and smaller in horizontal scale (which would imply faster average rotational speeds $U$, all other things being equal), the largest amplitude eddies $(\geq 30 \mathrm{~cm})$ are nearly all anticyclones (Figure $\mathrm{B} 2 \mathrm{a})$. This results in the average $U$ of anticyclones being $25.8 \mathrm{~cm} \mathrm{~s}^{-1}$ which is $1.4 \mathrm{~cm} \mathrm{~s}^{-1}$ faster than for cyclones (Figure B2c). The average eddy-induced Ekman pumping within $L_{s}$ of the centroids of anticyclones spawned from the Leeuwin Current is $7.8 \mathrm{~cm} \mathrm{day}^{-1}$ and the average Ekman downwelling within cyclones is -5.9 $\mathrm{cm}$ day $^{-1}$.

[75] The background average CHL gradient across the Leeuwin Current is predominantly eastward to northeastward (Figure 1b). This strong CHL gradient in the region where eddies form from the pinching off of meanders of the Leeuwin Current is manifest as a dipole structure of the composite mean of CHL" that is symptomatic of azimuthal advection of the ambient CHL field [Chelton et al., 2011b]. These dipole structures are clearest in the austral summertime when the 
a)
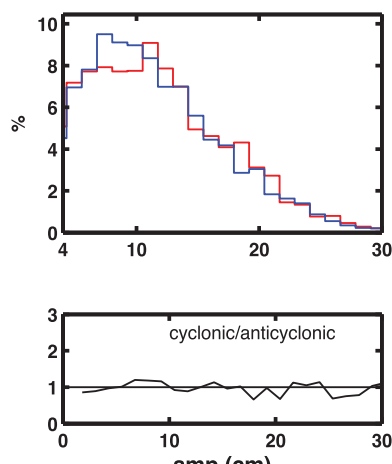

c)
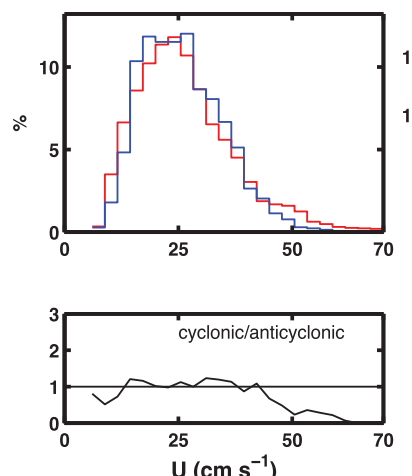

e)
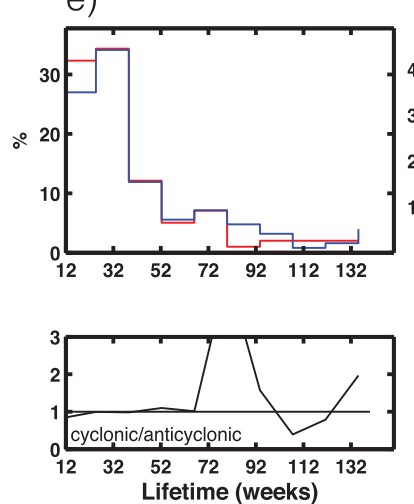

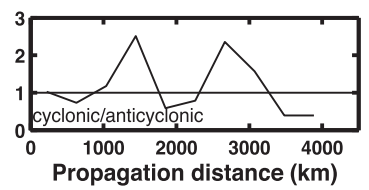

b)
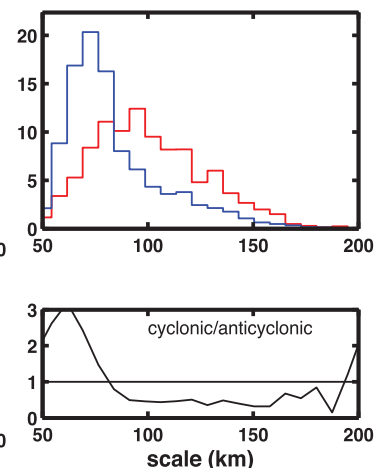

d)
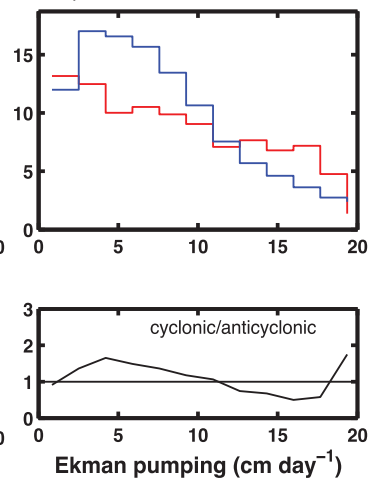

f)

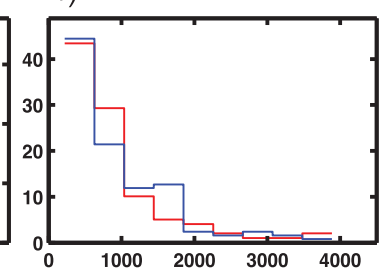

Propagation distance (km)

Figure B2. (top) Histograms with Leeuwin Current cyclones shown in blue and anticyclones in red and (bottom) the ratio of cyclonic to anticyclonic: (a) Eddy amplitudes; (b) eddy radius scales $L_{s}$; (c) maximum rotational speeds $U$ of the eddies; (d) magnitude of eddy-induced Ekman pumping within $L_{s} / 2$ of the eddy centroids; (e) eddy lifetime; and (f) propagation distance. As in Figure 4, Figures B2a-B2c and B2e-B2f are computed from the full 19 year $\mathrm{SSH}$ data record, Figure B2d is computed from the full 10 year QuikSCAT data record.

extrema for Leeuwin Current eddies are located in the northwest and southeast quadrants (Figure B3).

[76] The dipole structure of CHL" in Leeuwin Current eddies from advection of the zonal background CHL gradient dominates the composites of $\mathrm{CHL}^{\prime \prime}$ during the Austral summer (December through March, Figure B3). As winter approaches, CHL" in the interiors of Leeuwin Current anticyclones begins to respond to Ekman upwelling, with max-

imum CHL" occurring closer to the regions of maximum Ekman upwelling velocity, but always displaced somewhat to the northwest or north (Figure B3).

[77] The offset between the extrema of eddy-induced Ekman upwelling and CHL" is consistent with a superpositioning of a dipole structure from horizontal advection and a monopole structure collocated with contours of Ekman pumping velocity. This is shown schematically by combining a dipole CHL anomaly (top panel of Figure B4) with a monopole structure (middle panel of Figure B4), both with representative values of CHL". Their superposition results in a simulated composite CHL anomaly (bottom panel of Figure B4) that is similar to what is observed in Leeuwin Current anticyclones (Figure B3).

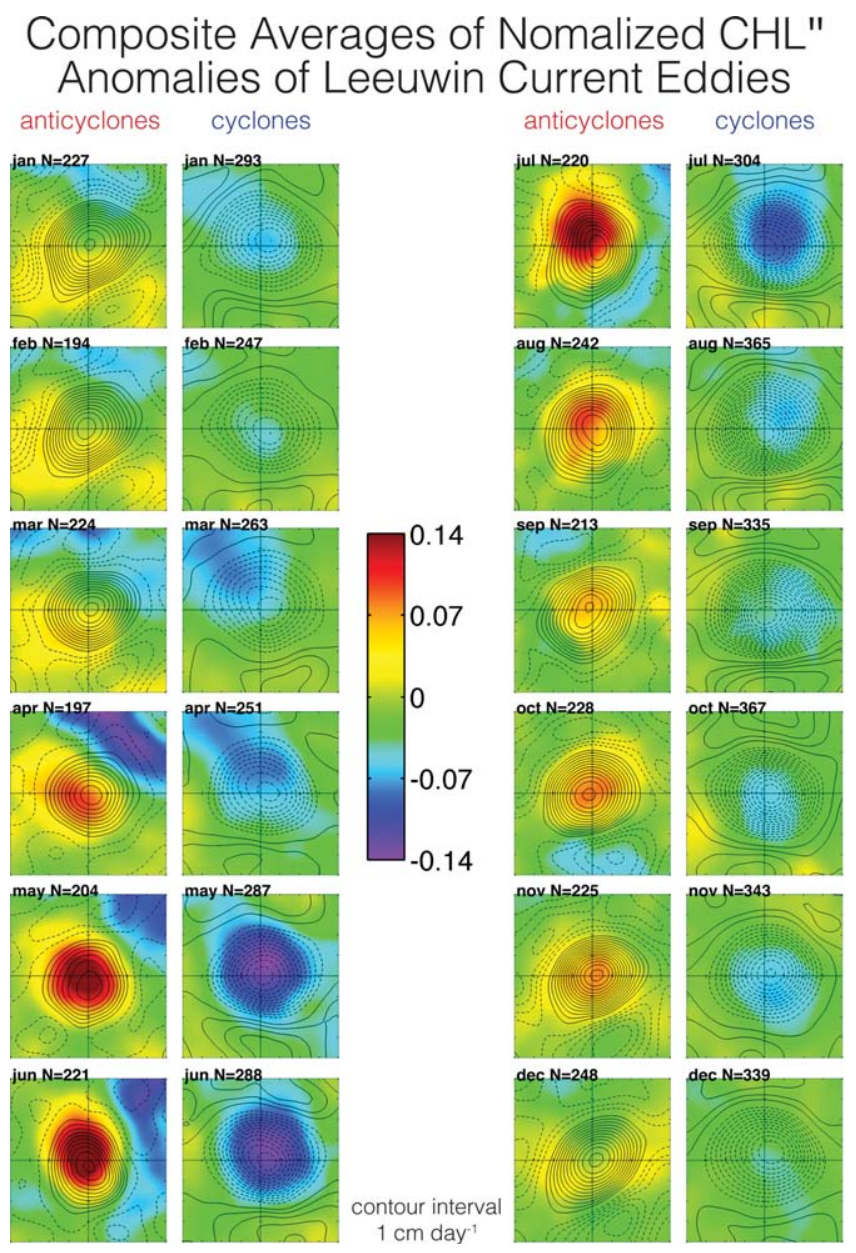

Figure B3. The same as Figure 5, except monthly composite averages of rotated and normalized $\mathrm{CHL}^{\prime \prime}$ of eddies originating in the Leeuwin Current, defined as the region $35^{\circ} \mathrm{S}-21^{\circ} \mathrm{S}$ and east of $108^{\circ} \mathrm{E}$ (Figure B1). The $x$ and $y$ coordinates of the composite averages are normalized by the eddy scale $L_{s}$. Contour interval of Ekman pumping velocity is $1 \mathrm{~cm}^{-1 a y}{ }^{-1}$ and negative velocities are shown as dashed curves. The left and right plots of each column of paired panels are for anticyclones and cyclones, respectively, for January (top left pair of plots) and progressing forward in time to December in the bottom right pair of plots. The title of each plot includes the number of eddy realizations used in the composite. 


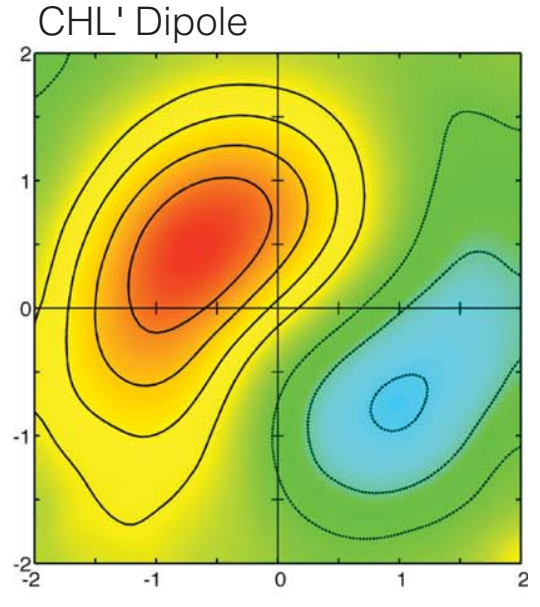

CHL' Monopole

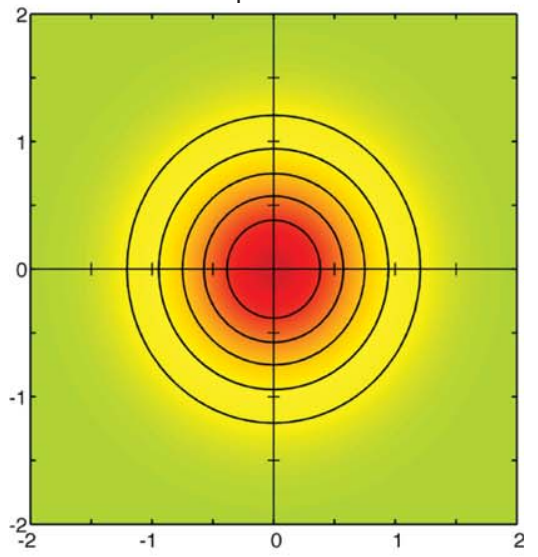

Combined $\mathrm{CHL}^{\prime}$

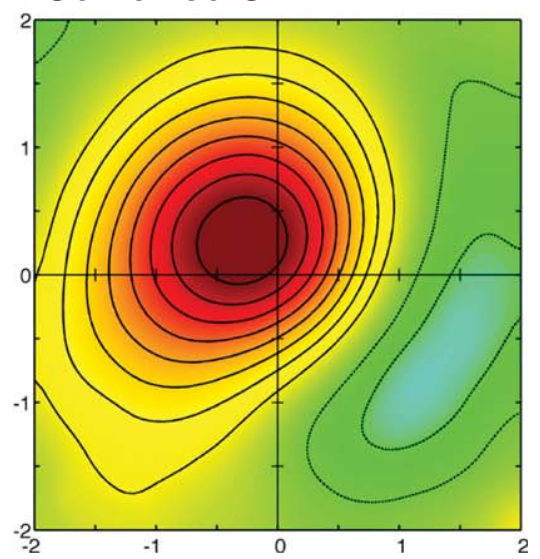

Figure B4. Simulated CHL anomaly composite consisting of the superposition of a dipole CHL anomaly resulting from the azimuthal advection of a predominately northeastward background $\mathrm{CHL}$ around the periphery of an anticyclonic SIO eddy (top row) with a monopole CHL anomaly resulting from eddy-induced Ekman upwelling (middle row). The combined composite (bottom row) is qualitatively similar to observed CHL anomalies composites of Leeuwin Current anticyclones (Figure B3).

[78] The primary mechanism for the monopole contribution to the CHL in the interiors of eddies in both the Leeuwin Current and SIO is thus the same eddy surface-current induced Ekman pumping. Ekman upwelling drives increased CHL" during the winter in anticyclones and downwelling drives decreased CHL" in cyclones throughout the year. As summarized above, this is augmented in the Leeuwin Current eddies by the advection of the background CHL around the eddy periphery in eddies of both polarities that results in dipoles during the Austral summer and small displacements of monopoles during Austral winter.

[79] As noted above, our criterion in section 3 of selecting eddies in the SIO based on a positive correlation $\geq 0.2$ between eddy $\mathrm{CHL}^{\prime}$ and Ekman pumping signatures results in nearly 3 times as many long-lived eddies compared with the restricted set of eddies that the automated procedure identified as having formed in the Leeuwin Current. It is, however, unlikely that nearly $2 / 3$ of the eddies analyzed in sections 3 and 4 are Leeuwin Current eddies that were "lost" and subsequently rediscovered by the eddy tracking procedure. Therefore, most of the eddies analyzed in sections 3 and 4 likely formed offshore of the Leeuwin Current, in the open SIO.

[80] As discussed in section 1, anticyclones formed in the poleward flowing Leeuwin Current preferentially entrain locally elevated CHL and nutrients during formation. The high initial CHL content of anticyclones is a key element of the Ekman pumping mechanism proposed in this study for maintenance of the CHL anomalies in the interiors of the anticyclones as they propagate westward into the interior SIO. A natural question that arises is why the eddies that form in the interior SIO respond to Ekman pumping in a manner similar to the response in Leeuwin Current eddies. The answer apparently lies in the baroclinic instability of the flow in the SIO [e.g., Smith, 2007]. Vertically sheared flow in the SIO interior evidently generates anticyclones that entrain high initial phytoplankton and nutrient concentrations.

[81] To investigate how instabilities in the sheared flow of the SIO, aside from the Leeuwin Current, can spawn anticyclones with locally elevated CHL and nutrient concentrations, we calculated the average total geostrophic current over the 9 year study period from the merged absolute dynamic topography fields distributed by CLS/AVISO. The absolute dynamic topography is estimated by adding a reference geoid to the merged SSH observations [see Rio et al., 2011, for details of how mapped absolute dynamic topography is constructed]. In the open ocean region enclosed by the 0.2 cross correlation contour, the dominant

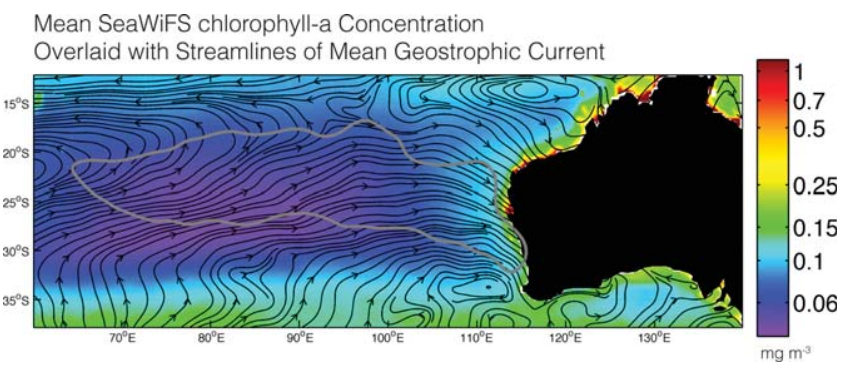

Figure B5. Mean CHL from SeaWiFS, plotted on a $\log _{10}$ scale, overlaid with streamlines of the mean total geostrophic currents, both averaged over the 8 year study period. The total geostrophic currents were computed from the AVISO mean dynamic topography. 

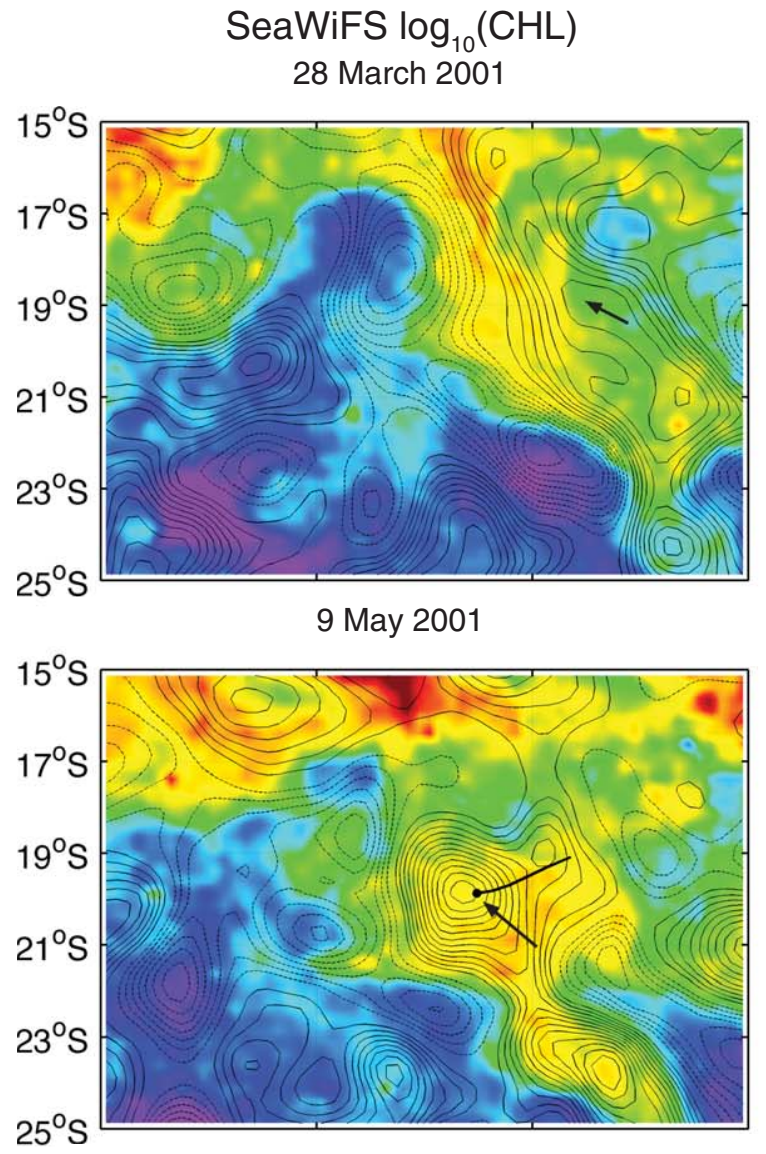

20 June 2001

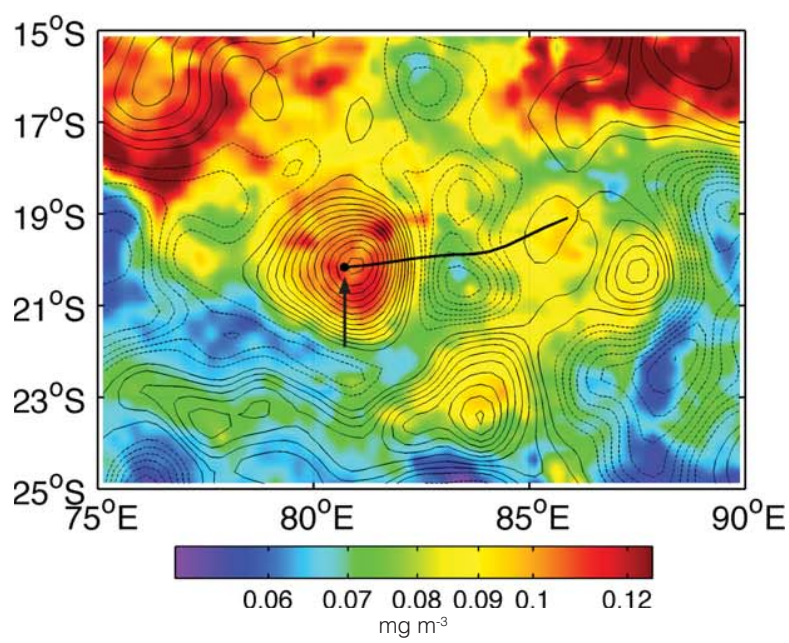

Figure B6. A series of SeaWiFS $\log _{10}$ (CHL) weekly averages illustrating the entrainment of the ambient CHL into an anticyclone formed in the open South Indian Ocean progressing forward in time from top to bottom. $\log _{10}$ (CHL) overlaid with contours of SSH at an interval of $2 \mathrm{~cm}$ staring at $\pm 2 \mathrm{~cm}$. Positive SSH anomalies (anticyclonic features) are shown as solid contours, negative SSH anomalies (cyclonic features) are shown as dashed curves. The black arrow point at the centroid of the anticyclonic eddies undergoing formation, whose trajectory is shown as a black track. Any gaps as a result of missing data were filed with linear interpolation to for image clarity. eddy-generating currents flow eastward and the ambient CHL gradient increases to the left of the current (Figure B5). Unstable meanders of these eastward currents pinch off and form isolated mesoscale eddies. As a result of the predominately northward ambient CHL gradient in this region, unstable counterclockwise rotating meanders entrain elevated CHL during the process of pinching off into anticyclonic eddies.

[82] A case study example of the preferential entrainment of locally elevated CHL into the interiors of anticyclones formed in the open SIO is illustrated in Figure B6. A westward propagating anticyclonic meander of the eastward current is observed to advect elevated $\mathrm{CHL}$, from north to south, along its western edge (Figure B6a). Eventually, this meander pinches off to form an isolated anticyclonic mesoscale eddy (Figures B6b and B6c). As a result of the preferential entrainment of elevated $\mathrm{CHL}$ into

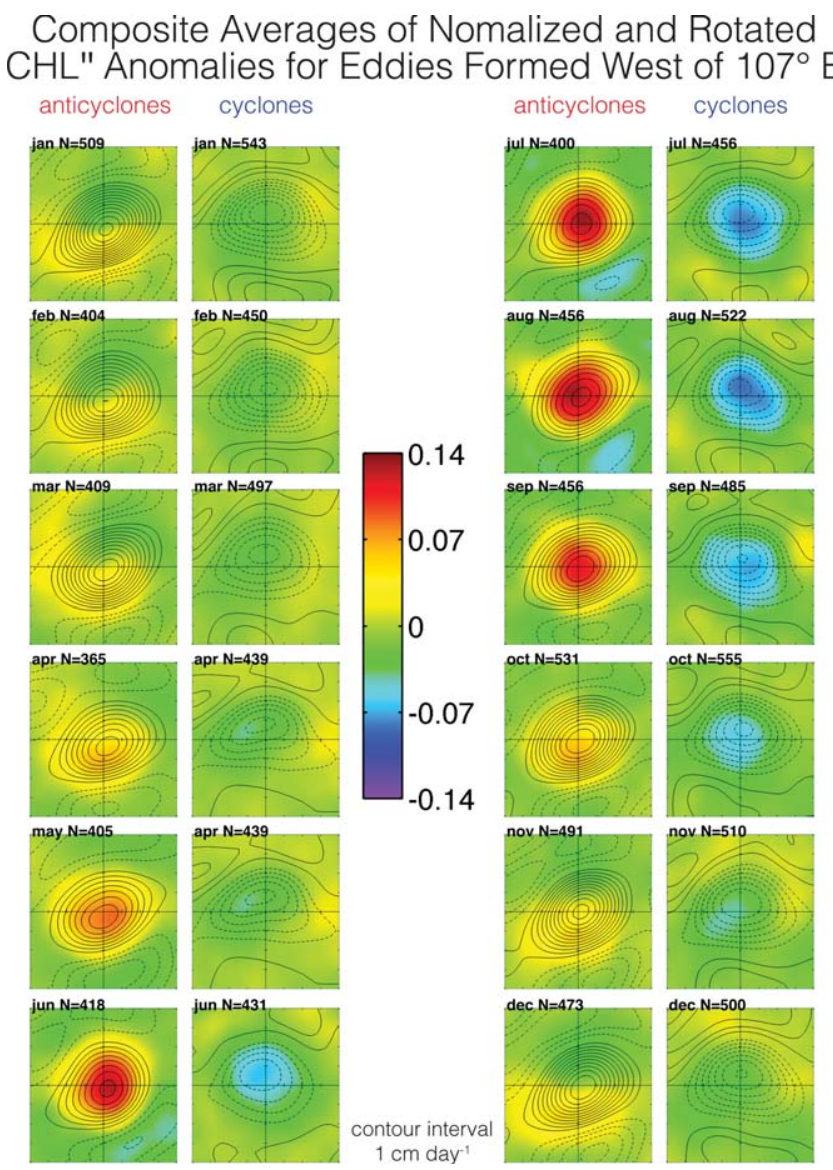

Figure B7. The same as Figure B3, except monthly composite averages of rotated and normalized $\mathrm{CHL}^{\prime \prime}$ of eddies originating west of $108^{\circ} \mathrm{E}$ and inside the 0.2 crosscorrelation contour shown in Figure 1d. The $x$ and $y$ coordinates of the composite averages are normalized by the eddy scale $L_{s}$. Contour interval of Ekman pumping velocity is 1 $\mathrm{cm}$ day $^{-1}$ and negative velocities are shown as dashed curves. The left and right plots of each column of paired panels are for anticyclones and cyclones, respectively, for January (top left pair of plots) and progressing forward in time to December in the bottom right pair of plots. The title of each plot includes the number of eddy realizations used in the composite. 


\section{Confidence Interval of the Composite Means}
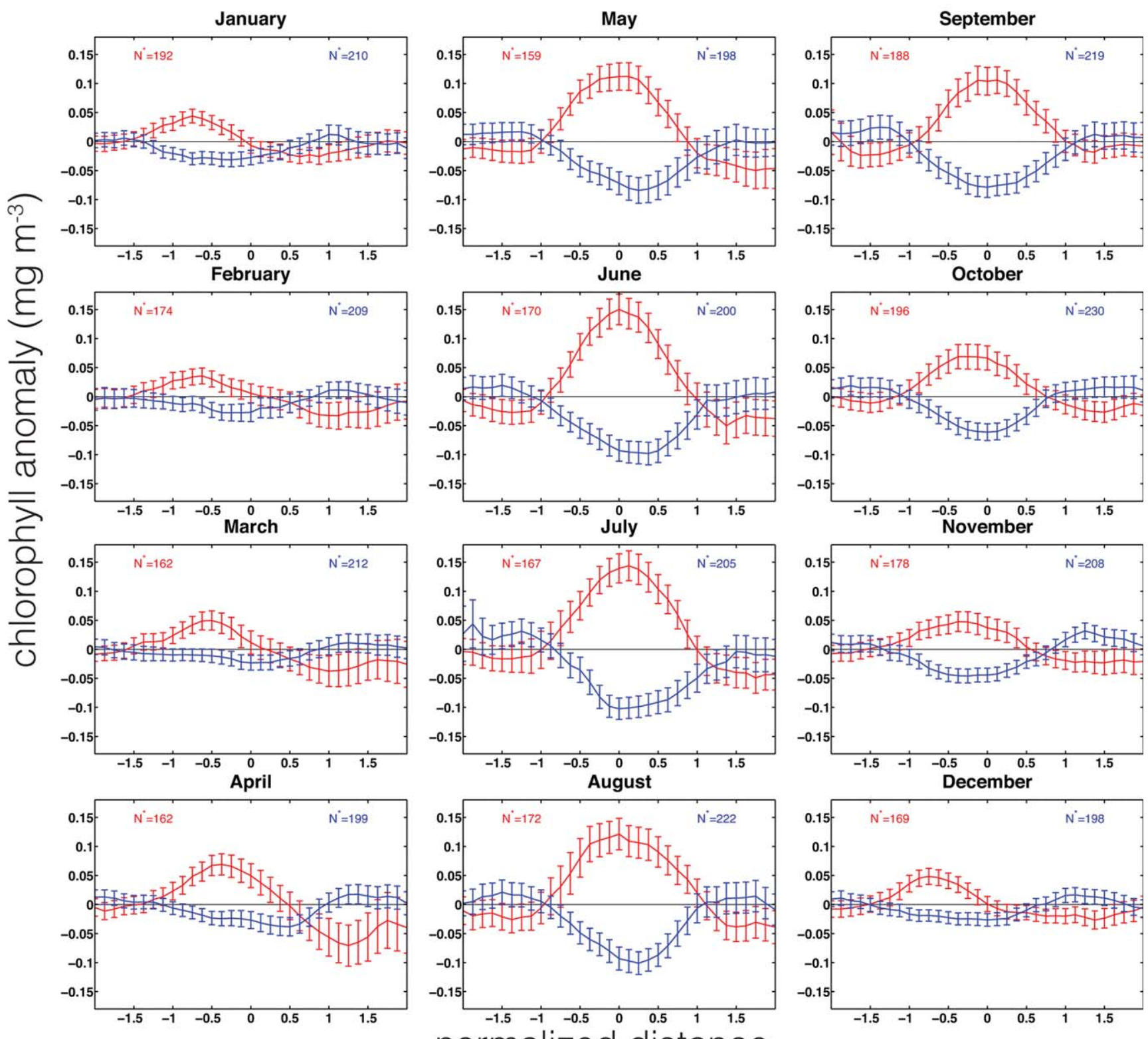

normalized distance

Figure C1. Confidence intervals about a diagonal transect taken from the southwest corner to northeast corner across each monthly composite mean (see Figure 5) of anticyclones in red and cyclones in blue. The $x$ axis is shown as distance from eddy centroid normalized by the eddy scale $L_{s}$. The effective degrees of freedom $N^{*}$ is reported in each plot for anticyclones in red and cyclones in blue.

anticyclones, a CHL response to eddy-induced Ekman pumping can be observed that is essentially the same as the CHL response in eddies that form in the Leeuwin Current with high initial CHL and nutrient concentrations.

[83] Clockwise rotating meanders in the SIO interior similarly entrain locally depressed CHL as they pinch off to form cyclonic eddies. Eddy-induced Ekman downwelling subsequently transports phytoplankton and nutrients out of the euphotic zone and reinforces the negative $\mathrm{CHL}^{\prime \prime}$ following the formation of these open-ocean cyclones.

[84] Composite averages were constructed by month for eddies generated in the interior of the SIO, described as all eddies identified by the automated eddy identification procedure as originating within the 0.2 cross correlation contour and west of $108^{\circ} \mathrm{E}$. Composite averages of these openocean eddies (Figure B7) are visually very similar to those shown in Figure 5.

\section{Appendix C : Confidence Intervals for Composites of Chlorophyll Anomalies}

[85] The non- $\log _{10}$ transformed $\mathrm{CHL}^{\prime \prime}$ have a maximum amplitude that approaches 0.15 at the eddy centroid during June and July (Figures 5 and C1). To test whether these 
small CHL" are significantly different from zero, we calculated the $95 \%$ confidence intervals for the composite mean of the CHL" for each month at each normalized location within the composites shown in Figure 5.

[86] The 95\% confidence interval for the mean is defined as $\pm \sigma(x, y) q_{t}\left(0.025, N^{*}-1\right) / \sqrt{N^{*}}$, where $\sigma(x, y)$ is the standard deviation of the $\mathrm{CHL}^{\prime \prime}$ estimates at any particular location within the composite average and $q_{t}(0.025$, $\left.N^{*}-1\right)$ is the 2.5 percentage point of the Students $t$ distribution with $N^{*}-1$ degrees of freedom, i.e., the numerical value that a Students $t$ random variable with $N^{*}-1$ degrees of freedom exceeds with $2.5 \%$ probability. We conservatively define $N^{*}$ to be the number of individual long-lived eddies (with lifetimes greater than or equal to 12 weeks) included in each composite rather than the nearly factor of three larger number of eddy realizations from which the composites were constructed.

[87] A diagonal transect from the southwest to the northeast across each monthly composite mean in Figure 5 is shown in Figure $\mathrm{C} 1$ as the mean $\mathrm{CHL}^{\prime \prime} \pm$ the $95 \%$ confidence interval for the mean. The diagonal transect was chosen to capture the dipole structure that dominates the spatial signature of $\mathrm{CHL}^{\prime \prime}$ during the summer (Figure 5). We conclude from Figure $\mathrm{C} 1$ that the maximum anomalies observed in the monthly composite averages of CHL" are generally significantly different from zero, even with our conservative choice of $N^{*}$.

[88] Acknowledgments. We thank Remote Sensing Systems (http://www.ssmi.com) for providing the QuikSCAT vector wind observations, Collecte Localis Satellites, AVISO (http://www.aviso.oceanobs.com) for the SSH observations, NASA MEaSUREs Ocean Color Product Evaluation Project (ftp://ftp.oceancolor.ucsb.edu/) for the CHL and $b_{b p}$ observations, NASA GSFC (http://oceancolor.gsfc.nasa.gov) for the $P A R$ and $k_{d}$ observations, Scripps Institution of Oceanography (UCSD), Argo Mixed Layers website (http://mixedlayer.ucsd.edu) for mixed layer depth data and NOAA NODC World Ocean Atlas 2005 for climatological temperature, salinity, and nitrate data (http:// www.nodc.noaa.gov). We also thank Allen Milligan, Ricardo Letelier, Ata Suanda, Toby Westberry, Dennis McGillicuddy, and Jason Graff for fruitful discussions in the preparation of this manuscript. We also thank Martin Hoecker-Martinez and Aurelie Moulin for helpful comments on the manuscript. This work was funded by NASA grants NNX08AI80G, NNX08AR37G, NNX10AO98G, and NNX13AD78G.

\section{References}

Anderson, L., D. McGillicuddy, M. Maltrud, I. Lima, and S. Doney (2011), Impact of eddy-wind interaction on eddy demographics and phytoplankton community structure in a model of the North Atlantic Ocean, Dyn. Atmos. Oceans, 52, 80-94.

Andrews, J. (1983), Ring structure in the poleward boundary current off Western Australia in summer, Mar. Freshwater Res., 34(4), 547-561.

Batteen, M., R. Kennedy, and H. Miller (2007), A process-oriented numerical study of currents, eddies and meanders in the leeuwin current system, Deep Sea Res., Part II, 54(8), 859-883.

Batteen, M. L., and M. J. Rutherford (1990), Modeling studies of eddies in the leeuwin current: The role of thermal forcing, J. Phys. Oceanogr., 20(9), 1484-1520.

Behrenfeld, M., E. Boss, D. Siegel, and D. Shea (2005), Carbon-based ocean productivity and phytoplankton physiology from space, Global Biogeochem. Cycles, 19(1), 1-14.

Behrenfeld, M., K. Halsey, and A. Milligan (2008), Evolved physiological responses of phytoplankton to their integrated growth environment, Philos. Trans. R. Soc. B, 363(1504), 2687-2703.

Campbell, J. (1995), The lognormal distribution as a model for bio-optical variability in the sea, J. Geophys. Res., 100, 13-13.
Chaigneau, A., M. Le Texier, G. Eldin, C. Grados, and O. Pizarro (2011), Vertical structure of mesoscale eddies in the eastern south pacific ocean: A composite analysis from altimetry and argo profiling floats, J. Geophys. Res., 116, C11025, doi:10.1029/2011JC007134.

Charria, G., F. Mélin, I. Dadou, M. Radenac, and V. Garçon (2003), Rossby wave and ocean color: The cells uplifting hypothesis in the South Atlantic subtropical convergence zone, Geophys. Res. Lett., 30(3), 1125, doi: 10.1029/2002GL016390.

Charria, G., I. Dadou, P. Cipollini, M. Drévillon, P. De Mey, and V. Garçon (2006), Understanding the influence of rossby waves on surface chlorophyll concentrations in the North Atlantic Ocean, J. Mar. Res., 64(1), 43-71.

Charria, G., I. Dadou, P. Cipollini, M. Drevillon, and V. Garcon (2008), Influence of rossby waves on primary production from a coupled physical-biogeochemical model in the North Atlantic Ocean, Ocean Sci., $4,199-213$.

Chelton, D., and M. Freilich (2005), Scatterometer-based assessment of 10$\mathrm{m}$ wind analyses from the operational ECMWF and NCEP numerical weather prediction models, Mon. Weather Rev., 133(2), 409-429.

Chelton, D., and M. Schlax (2003), The accuracies of smoothed sea surface height fields constructed from tandem satellite altimeter datasets, $J$. Atmos. Oceanic Technol., 20(9), 1276-1302.

Chelton, D., and S. Xie (2010), Coupled ocean-atmosphere interaction at oceanic mesoscales, Oceanogr. Mag., 23, 52-69.

Chelton, D., M. Schlax, and R. Samelson (2011a), Global observations of nonlinear mesoscale eddies, Prog. Oceanogr., 91(2), 167-216.

Chelton, D., P. Gaube, M. Schlax, J. Early, and R. Samelson (2011b), The influence of nonlinear mesoscale eddies on near-surface oceanic chlorophyll, Science, 334(6054), 328-332.

Cipollini, P., et al. (2001), Rossby waves detected in global ocean colour data, Geophys. Res. Lett., 28(2), 323-326.

Cresswell, G. (1977), The trapping of two drifting buoys by an ocean eddy, Deep Sea Res., 24(12), 1203-1209.

Dewar, W., and G. Flierl (1987), Some effects of the wind on rings, J. Phys. Oceanogr., 17(10), 1653-1667.

Doney, S., D. Glover, S. McCue, and M. Fuentes (2003), Mesoscale variability if sea-viewing wide filed-of-view sensor (seawifs) satellite ocean color: Global patterns and spatial scales, J. Geophys. Res., 108(C2), 3024, doi: 10.1029/2001JC000843.

Ducet, N., P. Le Traon, and G. Reverdin (2000), Global high-resolution mapping of ocean circulation from TOPEX/Poseidon and ERS-1 and-2, J. Geophys. Res., 105(C8), 19,477-19,498.

Early, J., R. Samelson, and D. Chelton (2011), The evolution and propagation of quasigeostrophic ocean eddies, J. Phys. Oceanogr., 41, 15351555.

Eden, C., and H. Dietze (2009), Effects of mesoscale eddy/wind interactions on biological new production and eddy kinetic energy, J. Geophys. Res., 114, C05023, doi:10.1029/2008JC005129.

Falkowski, P., and J. LaRoche (1991), Acclimation to spectral irradiance in algae, J. Phycol., 27(1), 8-14.

Fang, F., and R. Morrow (2003), Evolution, movement and decay of warmcore Leeuwin Current eddies, Deep Sea Res., Part II, 50(12-13), 22452261

Feng, M., C. Majewski, L. J. and Fandry, A. Waite (2007), Characteristics of two counter-rotating eddies in the Leeuwin current system off the Western Australian coast, Deep Sea Res., Part II, 54, 961-980.

Garver, S. A., and D. Siegel (1997), Inherent optical property inversion of ocean color spectra and its biogeochemical interpretation: I. Time series from the sargasso sea, J. Geophys. Res., 102, $18,607-18,625$.

Gaube, P. (2012), Satellite observations of the influence of mesoscale ocean eddies on near-surface temperature, phytoplankton and surface stress, PhD thesis, Oregon State Univ., 104 CEOAS Admin Bldg. Corvallis, Oregon.

Gaughan, D. J. (2007), Potential mechanisms of influence of the Leeuwin current eddy system on teleost recruitment to the western Australian continental shelf, Deep Sea Res., Part II, 54(8), 1129-1140.

Geider, R. (1987), Light and temperature dependence of the carbon to chlorophyll a ratio in microalgae and cyanobacteria: Implications for physiology and growth of phytoplankton, New Phytol., 106(1), 1-34.

Greenwood, J., M. Feng, and A. Waite (2007), A one-dimensional simulation of biological production in two contrasting mesoscale eddies in the south eastern Indian Ocean, Deep Sea Res., Part II, 54(8-10), 10291044. 
Griffin, D., J. Wilkin, C. Chubb, A. Pearce, and N. Caputi (2001), Ocean currents and the larval phase of Australian western rock lobster, Panulirus cygnus, Mar. Freshwater Res., 52(8), 1187-1200.

Gutknecht, E., I. Dadou, G. Charria, P. Cipollini, and V. Garcon (2010), Spatial and temporal variability of the remotely sensed chlorophyll a signal associated with rossby waves in the South Atlantic Ocean, J. Geophys. Res., 115, C05004, doi:10.1029/2009JC005291.

Hanson, C. E., S. Pesant, A. M. Waite, and C. B. Pattiaratchi (2007), Assessing the magnitude and significance of deep chlorophyll maxima of the coastal eastern Indian Ocean, Deep Sea Res., Part II, 54(8), 884 901.

Holl, C., A. Waite, S. Pesant, P. Thompson, and J. Montoya (2007), Unicellular diazotrophy as a source of nitrogen to Leeuwin current coastal eddies, Deep Sea Res., Part II, 54(8), 1045-1054.

Holte, J., and L. Talley (2009), A new algorithm for finding mixed layer depths with applications to argo data and subantarctic mode water formation, J. Atmos. Oceanic Technol., 26(9), 1920-1939.

Hutchinson, D. K., A. M. C. Hogg, and J. R. Blundell (2010), Southern ocean response to relative velocity wind stress forcing, J. Phys. Oceanogr., 40(2), 326-339.

Killworth, P., P. Cipollini, B. Uz, and J. Blundell (2004), Physical and biological mechanisms for planetary waves observed in satellite-derived chlorophyll, J. Geophys. Res., 109, C07002, doi:10.1029/ 2003JC001768.

Klein, P., A.-M. Treguier, and B. L. Hua (1998), Three-dimensional stirring of thermohaline fronts, J. Mar. Res., 56(3), 589-612.

Kunze, E. (1986), The mean and near-inertial velocity fields in a warmcore ring, J. Phys. Oceanogr., 16, 1444-1461.

Laws, E., and T. Bannister (1980), Nutrient-and light-limited growth of thalassiosira fluviatilis in continuous culture, with implications for phytoplankton growth in the ocean, Limnol. Oceanogr., 25(3), 457-473.

Ledwell, J., D. McGillicuddy Jr., and L. Anderson (2008), Nutrient flux into an intense deep chlorophyll layer in a mode-water eddy, Deep Sea Res., Part II, 55(10-13), 1139-1160.

Legeckis, R., and G. Cresswell (1981), Satellite observations of sea-surface temperature fronts off the coast of western and southern Australia, Deep Sea Res., Part I, 28(3), 297-306.

Lehahn, Y., F. d'Ovidio, M. Lévy, Y. Amitai, and E. Heifetz (2011), Long range transport of a quasi isolated chlorophyll patch by an Agulhas ring, Geophys. Res. Lett., 38, L16610, doi:10.1029/2011GL048588.

Lévy, M., and P. Klein (2004), Does the low frequency variability of mesoscale dynamics explain a part of the phytoplankton and zooplankton spectral variability?, Proc. R. Soc. London, Ser. A, 460(2046), 16731687

Lévy, M., P. Klein, and A. Treguier (2001), Impact of sub-mesoscale physics on production and subduction of phytoplankton in an oligotrophic regime, J. Mar. Res., 59(4), 535-565.

Lévy, M., R. Ferrari, P. Franks, A. Martin, and P. Rivière (2012), Bringing physics to life at the submesoscale, Geophys. Res. Lett., 39, L14602, doi:10.1029/2012GL052756.

Machu, E., B. Ferret, and V. Garçon (1999), Phytoplankton pigment distribution from seawifs data in the subtropical convergence zone south of Africa: A wavelet analysis, Geophys. Res. Lett., 26(10), 1469-1472.

Mahadevan, A., L. N. Thomas, and A. Tandon (2008), Comments on "eddy/wind interactions stimulate extraordinary mid-ocean plankton blooms", Science, 320, 448.

Maritorena, S., D. Siegel, and R. Peterson (2002), Optimization of a semianalytical ocean color model for global-scale applications, Appl. Opt. 41(15), 2705-2714

Martin, A., and K. Richards (2001), Mechanisms for vertical nutrient transport within a North Atlantic mesoscale eddy, Deep Sea Res., Part II, 48(4-5), 757-773.

McClain, C., S. Signorini, and J. Christian (2004), Subtropical gyre variability observed by ocean-color satellites, Deep Sea Res., Part II, 51(1), 281-301.

McClean, J., et al. (2011), A prototype two-decade fully-coupled fineresolution CCSM simulation, Ocean Modell., 39(1), 10-30.

McGillicuddy, D., and A. Robinson (1997), Eddy-induced nutrient supply and new production in the sargasso sea, Deep Sea Res., Part I, 44(8), $1427-1450$

McGillicuddy, D., et al. (2007), Eddy/wind interactions stimulate extraordinary mid-ocean plankton blooms, Science, 316(5827), $1021-1026$.
McGillicuddy, D., J. Ledwell, and L. Anderson (2008), Response to comments on "eddy/wind interactions stimulate extraordinary mid-ocean plankton bloom", Science, 320, 48c.

McWilliams, J., and G. Flierl (1979), On the evolution of isolated, nonlinear vortices, J. Phys. Oceanogr., 9(6), 1155-1182.

Moore, T., R. Matear, J. Marra, and L. Clementson (2007), Phytoplankton variability off the Western Australian Coast: Mesoscale eddies and their role in cross-shelf exchange, Deep Sea Res., Part II, 54(8-10), 943-960.

Morrow, R., F. Birol, D. Griffin, and J. Sudre (2004), Divergent pathways of cyclonic and anti-cyclonic ocean eddies, Geophys. Res. Lett., 31, L24311, doi: 10.1029/2004GL020974.

Muhling, B., L. Beckley, and M. Olivar (2007), Ichthyoplankton assemblage structure in two meso-scale Leeuwin current eddies, eastern Indian Ocean, Deep Sea Res., Part II, 54(8), 1113-1128.

Oschlies, A. (2002), Nutrient supply to the surface waters of the North Atlantic: A model study, J. Geophys. Res., 107(C5), 3046, doi:10.1029/ 2000JC000275.

Park, K., and P. Cornillon (2002), Stability-induced modification of sea surface winds over Gulf Stream rings, Geophys. Res. Lett., 29(24), 2211, doi:10.1029/2001GL014236.

Park, K., P. Cornillon, and D. Codiga (2006), Modification of surface winds near ocean fronts: Effects of Gulf Stream rings on scatterometer (QuikSCAT, NSCAT) wind observations, J. Geophys. Res., 111, C03021, doi: 10.1029/2005JC003016.

Paterson, H., B. Knott, and A. Waite (2007), Microzooplankton community structure and grazing on phytoplankton, in an eddy pair in the Indian ocean off western Australia, Deep Sea Res., Part II, 54(8-10), 10761093

Paterson, H., M. Feng, A. Waite, D. Gomis, L. Beckley, D. Holliday, and P. Thompson (2008), Physical and chemical signatures of a developing anticyclonic eddy in the Leeuwin Current, eastern Indian Ocean, J. Geophys. Res., 113, C07049, doi:10.1029/2007JC004707.

Pearce, A., and R. Griffiths (1991), The mesoscale structure of the Leeuwin Current: A comparison of laboratory models and satellite imagery, $J$. Geophys. Res., 96(C9), 16,739-16,757.

Qiu, B., and S. Chen (2005), Eddy-induced heat transport in the subtropical north pacific from Argo, TMI, and altimetry measurements, J. Phys. Oceanogr., 35(4), 458-473.

Rio, M., S. Guinehut, and G. Larnicol (2011), New CNES-CLS09 global mean dynamic topography computed from the combination of GRACE data, altimetry, and in situ measurements, J. Geophys. Res., 116, C07018, doi:10.1029/2010JC006505.

Roemmich, D., and J. Gilson (2001), Eddy transport of heat and thermocline waters in the north pacific: A key to interannual/decadal climate variability?, J. Phys. Oceanogr., 31(3), 675-687.

Ross, D., J. Overland, W. Plerson, V. Cardone, R. McPherson, and T. Yu (1985), Oceanic surface winds, Adv. Geophys., 27, 101-140.

Siegel, D., D. Court, D. Menzies, P. Peterson, S. Maritoena, and N. Nelson (2007), Satellite and in situ observation of the bio-optical signatures of two mesoscale eddies in the sargasso sea, Deep Sea Res., Part II, 55(10), $1218-1230$

Siegel, D., S. Maritorena, N. Nelson, D. Hansell, and M. Lorenzi-Kayser (2002), Global distribution and dynamics of colored dissolved and detrital organic materials, J. Geophys. Res., 107(C12), 3228, doi:10.1029/ 2001JC000965.

Siegel, D., P. Peterson, D. McGillicuddy Jr., S. Maritorena, and N. Nelson (2011), Bio-optical footprints created by mesoscale eddies in the sargasso sea, Geophys. Res. Lett., 38, L13608, doi:10.1029/ 2011 GL047660.

Small, R., S. DeSzoeke, S. Xie, L. O’Neill, H. Seo, Q. Song, P. Cornillon, M. Spall, and S. Minobe (2008), Air-sea interaction over ocean fronts and eddies, Dyn. Atmos. Oceans, 45(3-4), 274-319.

Smith, K. S. (2007), The geography of linear baroclinic instability in earth's oceans, J. Mar. Res., 65(5), 655-683.

Stern, M. (1965), Interaction of a uniform wind stress with a geostrophic vortex, Deep Sea Res. Oceanogr. Abstr., 12(3), 355-367.

Strzelecki, J., J. Koslow, and A. Waite (2007), Comparison of mesozooplankton communities from a pair of warm-and cold-core eddies off the coast of western Australia, Deep Sea Res., Part II, 54(8), 1103-1112.

Thomas, L. N. (2005), Destruction of potential vorticity by winds, J. Phys. Oceanogr., 35(12), 2457-2466.

Thomas, L. N., and P. B. Rhines (2002), Nonlinear stratified spin-up, J. Fluid Mech., 473, 211-244.

Thompson, P., S. Pesant, and A. Waite (2007), Contrasting the vertical differences in the phytoplankton biology of a dipole pair of eddies in the 


\section{GAUBE ET AL.: PHYTOPLANKTON AND EDDY-EKMAN PUMPING}

south-eastern Indian Ocean, Deep Sea Res., Part II, 54(8-10), 10031028.

Uz, B., and J. Yoder (2004), High frequency and mesoscale variability in SeaWiFS chlorophyll imagery and its relation to other remotely sensed oceanographic variables, Deep Sea Res., Part II, 51(10-11), 1001-1017.

Uz, B., J. Yoder, and V. Osychny (2001), Pumping of nutrients to ocean surface waters by the action of propagating planetary waves, Nature, 409(6820), 597-600.

Waite, A., S. Pesant, D. Griffin, P. Thompson, and C. Holl (2007a), Oceanography, primary production and dissolved inorganic nitrogen uptake in two Leeuwin Current eddies, Deep Sea Res., Part II, 54(8-10), 981-1002.
Waite, A., et al. (2007b), The Leeuwin Current and its eddies: An introductory overview, Deep Sea Res., Part II, 54(8-10), 789-796.

Waite, A., B. Muhling, C. Holl, L. Beckley, J. Montoya, J. Strzelecki, P. Thompson, and S. Pesant (2007c), Food web structure in two counterrotating eddies based on $\delta^{1} 5 \mathrm{n}$ and $\delta^{1} 3 \mathrm{c}$ isotopic analyses, Deep Sea Res., Part II, 54(8), 1055-1075.

Westberry, T., M. Behrenfeld, D. Siegel, and E. Boss (2008), Carbon-based primary productivity modeling with vertically resolved photoacclimation, Global Biogeochem. Cycles, 22, GB2024, doi:10.1029/ 2007GB003078. 